University of Wollongong

Research Online

Faculty of Engineering and Information

Faculty of Engineering and Information

Sciences - Papers: Part A

Sciences

$1-1-2015$

Impact of hazardous events on the removal of nutrients and trace organic contaminants by an anoxic-aerobic membrane bioreactor receiving real wastewater

Hop V. Phan

University of Wollongong, vhp997@uowmail.edu.au

Faisal I. Hai

University of Wollongong, faisal@uow.edu.au

James A. McDonald

University of New South Wales

Stuart J. Khan

University of New South Wales, s.khan@unsw.edu.au

Jason P. Van De Merwe

Griffith University

See next page for additional authors

Follow this and additional works at: https://ro.uow.edu.au/eispapers

Part of the Engineering Commons, and the Science and Technology Studies Commons

Research Online is the open access institutional repository for the University of Wollongong. For further information contact the UOW Library: research-pubs@uow.edu.au 


\title{
Impact of hazardous events on the removal of nutrients and trace organic contaminants by an anoxic-aerobic membrane bioreactor receiving real wastewater
}

\author{
Abstract \\ The impacts of four simulated hazardous events, namely, aeration failure, power loss, and chemical \\ shocks (ammonia or bleach) on the performance of an anoxic-aerobic membrane bioreactor (MBR) \\ receiving real wastewater were investigated. Hazardous events could alter $\mathrm{pH}$ and/or oxidation reduction \\ potential of the mixed liquor and inhibit biomass growth, thus affecting the removal of bulk organics, \\ nutrients and trace organic contaminants (TrOC). Chemical shocks generally exerted greater impact on \\ MBR performance than aeration/power failure events, with ammonia shock exerting the greatest impact. \\ Compared to total organic carbon, nutrient removal was more severely affected. Removal of the \\ hydrophilic TrOCs that are resistant and/or occur at high concentrations in wastewater was notably \\ affected. The MBR effectively reduced estrogenicity and toxicity from wastewater, but chemical shocks \\ could temporarily increase the endocrine activity of the effluent. Depending on the chemical shock-dose \\ and the membrane flux, hazardous events can exacerbate membrane fouling.

\section{Disciplines \\ Engineering | Science and Technology Studies}

\section{Publication Details} \\ Phan, H. V., Hai, F. I., McDonald, J. A., Khan, S. J., Van De Merwe, J. P., Leusch, F. D. L., Zhang, R., Price, W. \\ E., Broeckmann, A. \& Nghiem, L. D. (2015). Impact of hazardous events on the removal of nutrients and \\ trace organic contaminants by an anoxic-aerobic membrane bioreactor receiving real wastewater. \\ Bioresource Technology, 192 192-201.
}

\section{Authors}

Hop V. Phan, Faisal I. Hai, James A. McDonald, Stuart J. Khan, Jason P. Van De Merwe, Frederic D. L Leusch, Ren Zhang, William E. Price, Andreas Broeckmann, and Long D. Nghiem 


\title{
Impact of hazardous events on the removal of nutrients and trace organic contaminants by an anoxic-aerobic membrane bioreactor receiving real wastewater
}

\author{
Bioresource Technology \\ Volume 192, September 2015, Pages 192-201 \\ (doi:10.1016/j.biortech.2015.05.059)
}

Hop V. Phan ${ }^{\mathrm{a}}$, Faisal I. Hai ${ }^{\mathrm{a}^{*}}$, James A. McDonald ${ }^{\mathrm{b}}$, Stuart J. Khan ${ }^{\mathrm{b}}$, Jason P. van de Merwe ${ }^{\mathrm{c}}$, Frederic D. L. Leusch ${ }^{\mathrm{c}}$, Ren Zhang ${ }^{\mathrm{d}}$, William E. Price, Andreas Broeckmann ${ }^{\mathrm{f}}$, Long D. Nghiem $^{\mathrm{a}}$

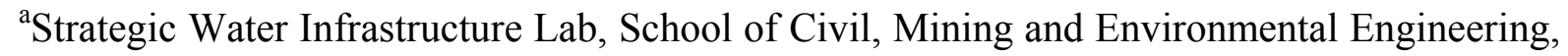
University of Wollongong, NSW 2522, Australia.

${ }^{\mathrm{b}}$ School of Civil and Environmental Engineering, University of New South Wales, NSW 2052, Australia.

'Smart Water Research Centre, Australian Rivers Institute, School of Environment, Griffith University, QLD 4222, Australia

${ }^{\mathrm{d}}$ Molecular Biology Lab, School of Biological Sciences, University of Wollongong, NSW 2522, Australia.

eStrategic Water Infrastructure Lab, School of Chemistry, University of Wollongong, NSW 2522, Australia.

${ }^{\mathrm{f}} \mathrm{GHD}, \mathrm{NSW} 2541$, Australia.

*Corresponding author: Faisal I. Hai (E-mail: faisal@,uow.edu..au; Phone: +61-2-4221-3054) 


\section{Highlights}

- Hazardous events affect performance by changing $\mathrm{pH}$, redox state or biomass content.

- Nutrient and trace organic removal was notably affected by hazardous events.

- Ammonia and bleach shocks slightly increased the effluent anti-estrogenic activity.

- Subject to membrane flux and toxic chemical dose, notable membrane fouling can occur

- Except for ammonia shock, MBR performance recovered within $72 \mathrm{~h}$ of hazardous events 


\begin{abstract}
The impacts of four simulated hazardous events, namely, aeration failure, power lost, and chemical shocks (ammonia or bleach) on the performance of an anoxic-aerobic membrane bioreactor (MBR) receiving real wastewater were investigated. Hazardous events could alter $\mathrm{pH}$ and/or oxidation reduction potential of the mixed liquor and inhibit biomass growth, thus affecting the removal of bulk organics, nutrients and trace organic contaminants (TrOC). Chemical shocks generally exerted greater impact on MBR performance than aeration/power failure events, with ammonia shock exerting the greatest impact. Compared to total organic carbon, nutrient removal was more severely affected. Removal of the hydrophilic TrOCs that are resistant and/or occur at high concentrations in wastewater was notably affected. The MBR effectively reduced estrogenicity and toxicity from wastewater, but chemical shocks could temporarily increase the endocrine activity of the effluent. Depending on the chemical shock-dose and the membrane flux, hazardous events can exacerbate membrane fouling.
\end{abstract}

Keywords: hazardous events; membrane bioreactor; trace organic contaminant (TrOC); nutrient removal; estrogenicity.

\title{
1. Introduction
}

In the field of water quality management, 'hazardous events' refer to departure from normal operational conditions including occurrence of changes in source water composition, extreme weather events, human error and mechanical malfunctions (Trinh et al., 2014). Hazardous events have been adopted by the World Health Organization (WHO) as a key parameter of risk management for the application of Water Safety Plans and the Guidelines for Drinking Water Quality (Bartram et al., 2009). Depending on both the likelihood and the consequences of these events, they may ultimately define the treatment reliability and level of risk regarding meeting final water quality objectives (Trinh, 2013).

Worldwide application of membrane bioreactors (MBRs) for wastewater treatment and reuse has been driven by increasingly stringent environmental regulations, freshwater scarcity and limited space availability. Advantages of MBRs over conventional activated sludge (CAS) processes have been assessed for removal of nutrient, bulk organics and trace organic contaminants (TrOCs) (Hai et al., 2014b). However, the validation of the robustness of the process to the risk of deviations in operating conditions during so called hazardous events has been scarce to date (Trinh et al., 2014).

Previous studies involving CAS processes indicate significant impact of hazardous events on wastewater treatment performance. For example, malfunction of the blowers/ diffusers can lead to temporary failure of the aeration system. Disruption of aeration results in inadequate dissolved oxygen and mixing, and may adversely affect nitrification (Burgess et al., 2002). A number of studies have also reported on the impact of chemical shock on CAS performance. Shock loading of common chemicals such as salt, ammonia and bleach can cause significant reduction in bulk organics and total nutrient removal (Bodík et al., 2008; Ding et al., 2014; Trinh et al., 2014). 
Notwithstanding the aforementioned reports about the detrimental impact of hazardous events on CAS processes, important research gaps exist. For example, power failure ceases feeding, aeration and mixing of sludge as well as recirculation between different reactors in biological nutrient removal processes that combine aerobic, anoxic and/or anaerobic conditions. Besides the possible consequences caused by aeration failure, interrupted sludge recirculation between reactors can impair nitrogen and phosphorous removal via nitrification/denitrification pathways and the polyphosphate accumulation/release processes, respectively. Such impacts have not been systematically studied to date. Furthermore, CAS performance under hazardous event circumstances may provide useful insights but may not completely represent impacts to MBR performance. MBRs combine membrane separation with biodegradation, and as such the potential impact of hazardous events on membrane hydraulic performance must be additionally considered. However, only one study (Trinh et al., 2015) to date has reported the impact of selected hazardous events on MBR performance. A further notable omission is that except for a limited coverage in the study of Trinh (2013), the impact of hazardous events on TrOC removal remains largely unexplored.

Taking into consideration the above research gaps, the aim of this study was to examine the impact of four hazardous events, namely, aeration failure, power loss, ammonia shock and bleach shock on the performance of an anoxic-aerobic MBR receiving real wastewater. Impacts on the characteristics of mixed liquor and the removal efficiency of bulk organics, nutrients as well TrOCs were systematically studied. The results of this study also provide unique insights to the impact of simulated hazardous events on effluent toxicity and estrogenicity.

\section{Methods}

The MBR was set up on the site of a full-scale MBR plant located in Kangaroo Valley, New South Wales, Australia. This experimental MBR rig was operated for total $270 \mathrm{~d}$. It was first operated for $145 \mathrm{~d}$ for acclimatization, performance stabilization and performance comparison with the full-scale MBR. Following this, four simulated hazardous events (aeration failure, power failure, ammonia shock and bleach shock) were conducted over a period of $125 \mathrm{~d}$ (Day 146 - 270) to assess the impacts on basic effluent quality parameters and on attenuation of TrOC concentration and toxicity/estrogenicity from effluent.

\subsection{MBR setup and operation}

The MBR comprised anoxic and aerobic reactors with working volumes of 14 and $12 \mathrm{~L}$, respectively. A hollow fiber ultrafiltration membrane (Zeweed-10 module, Zenon Environmental, Canada) was submerged in the aerobic reactor. With a nominal pore size of $0.04 \mu \mathrm{m}$ and an effective membrane surface area of $0.93 \mathrm{~m}^{2}$, the membrane was operated at an average flux of $1.2 \mathrm{~L} / \mathrm{m}^{2}$.h. To facilitate detachment of loosely attached particles on the membrane, effluent was extracted intermittently i.e., a relaxation period of 3 min every $10 \mathrm{~min}$ was applied. The MBR was operated at a solids retention time of $25 \mathrm{~d}$, a total hydraulic retention time of $1.5 \mathrm{~d}(0.8 \mathrm{~d}$ and $0.7 \mathrm{~d}$ for anoxic and aerobic reactors, respectively) and an internal recirculation ratio of 4 between anoxic-aerobic reactors. 
Transmembrane pressure (TMP) was continuously recorded via a high resolution $( \pm 0.1$ $\mathrm{kPa}$ ) vacuum gauge. In situ air scrubbing was found adequate to keep the TMP stable within $5 \mathrm{kPa}$ before conducting hazardous events experiments, and no chemical cleaning was required for the whole operation period. Feeding, recirculation and effluent extraction was performed with peristaltic pumps (Masterflex L/S, USA). The mixed liquor in the upper quarter of the pre-anoxic tank was intermittently ( $1 \mathrm{~min}$ on and $15 \mathrm{~min}$ off) mixed by a mixer $(200 \mathrm{rpm})$ to ensure that the sludge transferred from the aerobic tank did not get trapped within the anoxic tank. Mixed liquor temperature was stable at $18 \pm 3{ }^{\circ} \mathrm{C}$. During the steady state operation of MBR (before conducting hazardous events experiments), the mixed liquor $\mathrm{pH}$ was stable at $7.1 \pm 0.4(n=14)$ and $7.4 \pm 0.5(n=14)$ for the anoxic and aerobic bioreactors, respectively. Dissolved oxygen (DO) concentration in the bioreactors was maintained in the range of 2.5$5.0 \mathrm{mg} / \mathrm{L}$ for the aerobic zone and to below $0.25 \mathrm{mg} / \mathrm{L}$ for the anoxic zone.

\subsection{Hazardous events experiment protocol}

Four hazardous events, namely aeration failure, power failure, ammonia shock and bleach shock were selected based on a previously reported comprehensive literature review (Trinh et al., 2014). The MBR was subjected to the hazardous events in the following order: aeration failure (Day 146 -150); power failure (Day 174 - 178); ammonia shock (Day 231 - 234) and bleach shock (Day 258 - 261). The impact of the hazardous events on mixed liquor characteristics, membrane fouling and removal performance was assessed in terms of an array of selected parameters, namely, $\mathrm{pH}$, DO concentration and oxidation reduction potential (ORP) of the mixed liquor, mixed liquor suspended solids (MLSS) concentration, mixed liquor volatile suspended solids (MLVSS) concentration, TMP, total organic carbon (TOC), chemical oxygen demand (COD), $\mathrm{NH}_{4}{ }^{+}-\mathrm{N}, \mathrm{NO}_{2}{ }^{-}-\mathrm{N}, \mathrm{NO}_{3}{ }^{-}-\mathrm{N}, \mathrm{PO}_{4}{ }^{3-}-\mathrm{P}$ as well as TrOCs and toxicity/estrogenicity.

To differentiate between the impacts of different hazardous events and to distinguish the changes due to hazardous events from that due to ambient variability in operational conditions, the following controls were in place:

(i) A monitoring period between the hazardous events was allowed to confirm retrieval of process stability;

(ii) Primary settled wastewater was collected weekly to a reservoir, and the same influent was fed to the MBR before, during and after the hazardous events over the week. It was also confirmed that the wastewater characteristics in terms of TOC, TN and TrOC did not change significantly during storage and use (data not shown).

(iii) Other key operational parameters were either controlled or remained stable as described in Section 2.1.

\subsubsection{Aeration and power failure}

Aeration failure was simulated by ceasing aeration in the aerobic reactor for $18 \mathrm{~h}$. The power failure was simulated by terminating the power supply to the MBR system for 18 h. Accordingly, influent feeding, aeration of the aerobic reactor, mixing of the anoxic 
reactor, and the sludge recirculation between aerobic and anoxic reactors were ceased for $18 \mathrm{~h}$. Effluent withdrawal was discontinued during the periods without aeration or power supply, and samples were collected immediately before and 1, 3, 24 and $72 \mathrm{~h}$ after the resumption of the aeration or power supply (i.e., the first sample after the shock was collected at the $19^{\text {th }}$ hour).

\subsubsection{Chemical shock}

Chemical shocks (ammonia and bleach separately) were introduced as a single dose directly to the bioreactors, and samples were collected just before and 1, 3, 24 and $72 \mathrm{~h}$ immediately after the shock application.

In line with the protocols used in previous CAS (Ding et al., 2014) and MBR (Trinh et al., 2015) studies, a $\mathrm{NH}_{4}{ }^{+}-\mathrm{N}$ concentration of $1000 \mathrm{mg} / \mathrm{L}$ (approximately 10 times the average concentration of $\mathrm{NH}_{4}{ }^{+}-\mathrm{N}$ in the raw sewage) was selected as a shock dose. This was applied in the form of ammonium bicarbonate $\left(\mathrm{NH}_{4} \mathrm{HCO}_{3}\right)$.

Only two studies related to the impact of bleach on activated sludge processes were found. While Bodik et al. (2008) demonstrated a significant effect of disinfectants containing sodium hypochlorite $(0.3 \mathrm{~mL} / \mathrm{L})$ on organics removal by activated sludge in batch tests, no discernible effect of a bleach dose of $0.4 \mathrm{~mL} / \mathrm{L}$ on the performance of bench- or pilot-scale MBRs was observed by Knops (2010). Accordingly in the current study, bleach shock was conducted by a single dose of $0.8 \mathrm{~mL} / \mathrm{L}$ of commercial bleach (Domestos, Unilever) to the mixed liquor of both bioreactors, i.e., $38 \mathrm{ppm}$ of active chlorine, plus $9.6 \mathrm{ppm}$ of sodium hydroxide and $0.4 \mathrm{ppm}$ of alkaline salts (active ingredients of Domestos bleach: sodium hypochlorite $49.9 \mathrm{~g} / \mathrm{L}$, active chlorine $4.75 \%$ $(\mathrm{m} / \mathrm{v})$, sodium hydroxide $12.0 \mathrm{~g} / \mathrm{L}$ and alkaline salts $0.5 \mathrm{~g} / \mathrm{L})$.

\subsection{Sample analysis}

\subsubsection{Analysis of basic parameters}

TOC and $\mathrm{TN}$ were analyzed using a TOC/TN-V $\mathrm{V}_{\mathrm{CSH}}$ analyser (Shimadzu, Japan). COD was analyzed using COD vials (0-1500 ppm, WatertestSystems, Australia) with a Hach DR 5000 spectrophotometer according to the Standard Method 5220 D (Eaton et al., 2005). $\mathrm{NH}_{4}{ }^{+}-\mathrm{N}$ and ortho- $\mathrm{PO}_{4}{ }^{3-}-\mathrm{P}$ concentrations were measured using flow injection analysis (Lachat instruments, Milwaukee, USA) following the Standard Methods 4500$\mathrm{NH}_{3} \mathrm{H}$ and 4500-P G, respectively (Eaton et al., 2005). MLSS and MLVSS concentrations in bioreactors were measured according to the Standard Method 2540 (Eaton et al., 2005).

\subsubsection{Trace organic contaminant analysis}

In total, 45 TrOCs including 27 PPCPs, four industrial chemicals, eight steroid hormones and six pesticides were monitored in this study (Supplementary Data Table 1). Influent and MBR effluent samples $(0.5 \mathrm{~L})$ were collected and immediately transferred to the laboratory. The influent samples were filtered through $1 \mu \mathrm{m}$ and then $0.45 \mu \mathrm{m}$ glass-fiber filter papers (Millipore, Australia). The effluent (membranepermeate) samples were not further filtered. Concentrations of TrOCs were determined 
using an analytical method previously described by Phan et al. (2015). This method involves solid phase extraction (SPE) using Oasis HLB cartridges (Waters, Millford, MA, USA) followed by analytical quantification by high performance liquid chromatography (Agilent 1200 series, Palo Alto, CA, USA) coupled with tandem triple quadrupole mass spectrometer (API 4000, Applied Biosystems, Foster City, CA, USA) in positive and negative electro-spray modes as well as atmospheric pressure chemical ionization (APCI) in positive mode. Isotope dilution was used for SPE correction of all analytes. Sludge samples were extracted by a previously developed solvent extraction method (Wijekoon et al., 2013) prior to analysis as described above.

\subsubsection{Estrogenicity and toxicity analysis}

The filtered influent and MBR effluent samples $(0.5 \mathrm{~L})$ were extracted on Oasis HLB solid-phase cartridges preconditioned and eluted with $2 \times 10 \mathrm{~mL}$ methanol and reconstituted in $500 \mu \mathrm{L}$ methanol. This resulted in a relative enrichment factor of 1000 (i.e., each sample was concentrated 1000 times). Estrogenicity in solid-phase extracts was measured using GeneBLAzer ER $\alpha$-UAS-bla GripTite cells (Life Technologies, Carlsbad, CA), following methods described by Escher et al. (2014) and the manufacturers protocols, with slight modifications. The GeneBLAzer ER $\alpha$ assay is a reporter gene assay that measures estrogen receptor-mediated gene activation, indicating the presence of estrogens or estrogen mimics in the sample. The assay was performed in 384-well plate format, run in both agonist and antagonist (in combination with an $\mathrm{EC}_{80}$ concentration of the agonist) modes, and a 2-4 point serial dilution of each sample was tested on at least two separate occasions. Fluorescence was measured in a Fluostar plate reader (BMG Labtech, Germany) at 460 and $520 \mathrm{~nm}$ after excitation at $410 \mathrm{~nm}$, and the data expressed as the ratio of fluorescence at 460 divided by 520 . The results were then compared to a concentration-effect curve with the reference standards and expressed as $17 \beta$-estadiol (agonist) and tamoxifen (antagonist) equivalent concentrations. The limits of detection were $0.01 \mathrm{ng} / \mathrm{L}$ and $6 \mu \mathrm{g} / \mathrm{L}$ for $17 \beta$-estadiol (EEQ) and tamoxifen (TMXEQ) equivalent concentrations, respectively.

The aquatic toxicity of the solid-phase extracts was assessed using the bacterial luminescence toxicity screen (BLT-Screen) described by van de Merwe and Leusch (2015). Briefly, solid-phase extracts were added to phosphate-buffered saline medium and serially diluted in a 96-well plate, which also contained a reference compound (pentachlorophenol), negative controls and inter-assay samples for quality control. Naturally luminescent bacteria, Photobacterium leiognathi, was then added to each well (from a cryopreserved stock) to mark the start of the exposure period. Exactly 30 minutes later the luminescence of each well was measured in a Fluostar plate reader (BMG Labtech, Germany), and the inhibition of luminescence was calculated relative to controls. The toxicity of each sample was expressed as relative Toxic Unit (rTU), the reciprocal of the IC(REF)20.

\section{Results and discussion}

\subsection{Impact on mixed liquor characteristics}

3.1.1 $\mathrm{pH}$ and $\mathrm{ORP}$ 
Except for the ammonia shock event, mixed liquor $\mathrm{pH}$ was within the normal operation range during all simulated hazardous events (Supplementary Data Figure S2). The mixed liquor $\mathrm{pH}$ increased from 7.1 to 8.3 and 7.2 to 8.4 for the anoxic and the aerobic bioreactors, respectively following ammonia shock. In agreement with Trinh (2013), the $\mathrm{pH}$ levels returned to the normal operation range within $72 \mathrm{~h}$. Such temporary $\mathrm{pH}$ variation may not significantly affect bulk organics removal since the optimum $\mathrm{pH}$ for biological process is thought to lie between pH 6.5 and 8.0 (Baldwin \& Campbell, 2001). However, this may have significant impact on the removal of some specific TrOCs as further discussed in Section 3.3.

As expected, the mixed liquor ORP of both reactors instantly decreased due to aeration/power failure and ammonia shock, while the ORP of the anoxic reactor increased from -40 to $53 \mathrm{mV}$ immediately $(1 \mathrm{~h})$ after applying the bleach shock (Supplementary Data Figure S3), although in all cases the ORP levels returned to their original levels within $24 \mathrm{~h}$. Biological nutrient removal is extremely sensitive to ORP in bioreactors, and different metabolic processes, namely, nitrification, denitrification and phosphate accumulation/release dominate in different ORP ranges (Phan et al., 2014). Therefore, the observed ORP swing was likely a key reason for the disruption in nutrient removal as discussed in Section 3.2.2.

\subsubsection{MLSS and MLVSS concentration}

Of the entire period of the MBR operation (270 d), the aerobic MLSS concentration was at its highest immediately prior to the application of ammonia shock (Day 231). This may have been caused by the high suspended solid concentration in the influent that was fed to the MBR from Day 210 to 234. The influent suspended solid concentration in that period was $0.6 \mathrm{~g} / \mathrm{L}$ (approximately 10 times the usual suspended solid concentration in influent, $0.06 \pm 0.07 \mathrm{~g} / \mathrm{L}, n=26)$. Ammonia shock caused notable gradual reduction in MLVSS concentration (aerobic: from 2.6 to $2.0 \mathrm{~g} / \mathrm{L}$; anoxic from 2.5 to $1.6 \mathrm{~g} / \mathrm{L}$ ) and MLVSS/MLSS ratio (aerobic: $0.59-0.55$; anoxic: $0.73-0.51$ ) (Supplementary Data Figure S4), and possibly contributed to the observed reduction in bulk organics, nutrient and TrOC removal (see Section 3.2 and 3.3). The observed impact of ammonia shock on MLVSS concentration was expected as it has been demonstrated to inhibit the growth of activated sludge (Ding et al., 2014). A similar impact of ammonia shock on sludge concentration was observed in a previous MBR study (Trinh, 2013). In the current study, $18 \mathrm{~h}$ power failure caused notable reduction in aerobic MLVSS concentration (2.5 - $1.5 \mathrm{~g} / \mathrm{L})$ which did not recover within $72 \mathrm{~h}$, while the MLVSS concentration was only slightly affected due to $18 \mathrm{~h}$ aeration failure (Supplementary Data Figure S4). Although sludge lysis was evident through the brownish color in effluent which appeared within $1 \mathrm{~h}$ of adding bleach and continued for the next $72 \mathrm{~h}$ (data not shown), little variation in MLVSS or MLSS concentration was observed. This may be attributed to the fact that among all the hazardous events, the influent TOC (200 mg/L) and TN (75 mg/L) during bleach shock was the highest, which perhaps sustained the sludge concentration despite sludge lysis by bleach.

\subsection{Impact on bulk organics and nutrient removal}


The influent TOC, COD and TN concentrations to the MBR varied significantly (TOC $=110 \pm 50 \mathrm{mg} / \mathrm{L}, n=41 ; \mathrm{COD}=210 \pm 120 \mathrm{mg} / \mathrm{L}, n=29 ;$ and $\mathrm{TN}=50 \pm 20 \mathrm{mg} / \mathrm{L}, n=$ 41) over the observation period. Thus the bulk organics and nutrient removal efficiency also fluctuated considerably (Supplementary Data Figure S5). Nevertheless, the impacts of hazardous events were investigated at periods of stable TOC, COD and TN removal.

\subsubsection{TOC and COD removal}

In agreement with a recent study on the impact of oxygen cut off and starvation conditions on biological activity of activated sludge (Villain et al., 2013), in this study, aeration and power failure caused slight and temporary drops in TOC and COD removal (Supplementary Data Figure S6 and S7). Conversely, ammonia shock led to immediate loss of TOC removal capacity by the MBR, and no removal was observed for $24 \mathrm{~h}$, although the removal performance significantly recovered within $72 \mathrm{~h}$ (Figure 1). A significant but less prominent impact of ammonia shock on COD removal was also observed. While the impact of ammonia shock observed in the current study generally resonates with that from previous CAS and MBR studies (Ding et al., 2014; Trinh et al., 2015), the results from this study additionally indicate that TOC may be a more sensitive parameter than COD to assess the impact of these types of hazardous events.

Bodik et al. (2008) reported a 30-100\% drop in COD removal due to bleach dosage of $4.75-47.5 \mathrm{mg} \mathrm{Cl}_{2} / \mathrm{g}$ MLSS in batch tests. However, although an average bleach dosage of ca. $13 \mathrm{mg} \mathrm{Cl}_{2} / \mathrm{g}$ MLSS was applied in the current study, in agreement with the MBR study of Knops (2010), a negligible impact of bleach shock on TOC and COD removal was observed (Supplementary Data Figure S8). The discrepancy between the observations made in the current study and that in Bodik et al. (2008) highlights that relying on batch tests only to predict the impact on continuous flow MBRs may be misleading.

\subsubsection{Nutrient removal}

All hazardous events, most significantly ammonia shock, caused significant deterioration in TN and ammonia removal. Notably, addition of $\mathrm{NH}_{4} \mathrm{HCO}_{3}$ to achieve a $\mathrm{NH}_{4}{ }^{+}-\mathrm{N}$ concentration of $1000 \mathrm{mg} / \mathrm{L}$ caused an instantaneous additional TOC and TN load of 670 and $780 \mathrm{mg} / \mathrm{L}$, respectively. In addition to this increased TOC and TN load, ammonia is notorious for its cytotoxic effects. Furthermore, ammonia shock caused increase in mixed liquor $\mathrm{pH}$ and decrease in biomass concentration (see Section 3.1). Consequently, ammonia shock led to an immediate and complete cessation of TN and ammonia removal for $24 \mathrm{~h}$ (Figure 2), and only a $25 \%$ recovery of $\mathrm{TN}$ and ammonia removal was observed within $72 \mathrm{~h}$. By contrast, a 10-30\% reduction in TN removal was observed during the other hazardous events, and a complete recovery was usually observed within 72 h (Supplementary Data Figure S6-8).

The drop in ammonia and TN removal was accompanied by the appearance of nitrite in effluent (Figure 2). The appearance of nitrite following ammonia shock indicates impaired nitrification, i.e., incomplete conversion of ammonia, which may be attributed to the elevated ammonia load as well as the inhibition of the nitrifiers due to oxygen limitation caused by ammonia shock. Similar to the current study, ammonia shock to a 
pilot-scale aerobic CAS system led to a sharp increase of ammonia concentration with the concurrent occurrence of nitrite in effluent (Burgess et al., 2002). However, an additional aspect revealed in this study was the increase in nitrate concentration (following an initial drop), with simultaneous detection of nitrite in effluent (Figure 2). This suggests that not only nitrification (i.e., conversion of ammonia to nitrate) but also denitrification (i.e., conversion of nitrate to nitrogen gas) was affected. This can be explained by the changes in ORP and MLVSS concentrations caused by the hazardous events (See Section 3.1). Notably, ammonia removal recovery was confirmed $10 \mathrm{~d}$ following the ammonia shock, while that of TN was not achieved before an additional 7 $\mathrm{d}$ (data not shown), possibly indicating that the denitrifiers were more susceptible to ammonia shock.

The MBR was not specifically designed for phosphate removal. For example, it lacked a strictly anaerobic reactor. Accordingly, the $\mathrm{PO}_{4}{ }^{3-}-\mathrm{P}$ removal performance was poor throughout this study $(32 \pm 16 \%, n=18)$, except for the period of Day $174-190$ and Day $231-248$, when the $\mathrm{PO}_{4}{ }^{3-}-\mathrm{P}$ removal was as high as 96 and $90 \%$, respectively. The power failure and ammonia shock events coincided with the periods of high $\mathrm{PO}_{4}{ }^{3-}-\mathrm{P}$ removal, and a significant impact of these hazardous events on $\mathrm{PO}_{4}{ }^{3-}-\mathrm{P}$ removal performance was observed. For example, ammonia shock resulted in a complete cessation of $\mathrm{PO}_{4}{ }^{3-}-\mathrm{P}$ removal for $24 \mathrm{~h}$, although the removal was recovered entirely within $72 \mathrm{~h}$ after shock load (Figure 2). Similarly, the samples taken after $1 \mathrm{~h}$ of resuming power supply showed a $73 \%$ drop in $\mathrm{PO}_{4}{ }^{3-}-\mathrm{P}$ removal (Supplementary Data Figure 9), possibly due to release of stored $\mathrm{PO}_{4}{ }^{3-}-\mathrm{P}$ via biomass autolysis under starvation conditions The impact of aeration failure and bleach shock was significant but less pronounced, which may be attributed to the fact that $\mathrm{PO}_{4}{ }^{3-}-\mathrm{P}$ removal was already low even before these hazardous events were conducted (Supplementary Data Figure 10 and 11).

\subsection{Impact on trace organic contaminant removal}

Among the 45 TrOCs monitored (Supplementary Data Table S1), 13 compounds were consistently detected in influent samples during the experimental period of four simulated hazardous events, while 13 TrOCs were detected only occasionally (Figure $3)$.

\subsubsection{Aqueous phase removal}

The MBR achieved high removal ( $>90 \%)$ of significantly hydrophobic TrOCs, namely, polyparaben, estrone, etiocholanolone, androsterone and $17 \beta$-estradiol irrespective of the hazardous events (Figure 3). These compounds possess similar chemical backbone structures, and the fact that they were not detected in sludge (see Section 3.3.2) confirmed their removal by biotransformation. High biodegradability of these TrOCs can be attributed to the presence of a strong electron withdrawing group hydroxyl in their structures (Alexander et al., 2012; Hai et al., 2012a; Tadkaew et al., 2011). On the other hand, negligible to up to $25 \%$ removals of the well-known resistant compounds diclofenac, carbamazepine, primidone and amitriptyline were observed throughout the experimental period. Occurrence of strong electron withdrawing groups and/or absence 
of electron donating groups is thought to be related to their poor removal by CAS processes or MBRs (Hai et al., 2014a).

A significant impact of one or more hazardous events was noted in the case of removal of eight pharmaceuticals, namely, atenolol, sulfamethoxazole, naproxen, trimethoprim, ibuprofen, paracetamol, caffeine, and triclosan. With the exception of triclosan, all of these TrOCs are significantly hydrophilic and thus biodegradation can be considered the main mechanism of their removal by MBR. Similar to TOC or TN removal, ammonia and bleach shocks were generally observed to exert greater impact on $\mathrm{TrOC}$ removal than aeration and power failure events (Figure 3).

Atenolol, caffeine, ibuprofen and paracetamol are generally classified as easily biodegradable (Hai et al., 2014a; Tadkaew et al., 2011), but in this study a significant reduction in removal efficacy was noted for these TrOCs after the hazardous events. Consistent with the available literature, in this study, over $90 \%$ removal of atenolol was observed (Figure 3). However, a 5-10\% reduction in atenolol removal was noted during the hazardous events. The presence of the strong electron donating group amine in atenolol is thought to make it amenable to biodegradation (Tadkaew et al., 2011), but atenolol also contains a strong electron withdrawing group (amide), which perhaps renders its removal by MBR susceptible to process changes. Nevertheless, in all instances a complete recovery of atenolol removal was achieved within $72 \mathrm{~h}$. Paracetamol was detected in raw sewage at concentrations up to $120 \mu \mathrm{g} / \mathrm{L}$. Due to bleach shock, its concentration in effluent increased significantly from below detection limit $(<5 \mathrm{ng} / \mathrm{L})$ to approximately $200 \mathrm{ng} / \mathrm{L}$ within $1 \mathrm{~h}$ of bleach addition. During the observation period, the raw sewage caffeine concentration varied over $13-98 \mu \mathrm{g} / \mathrm{L}$. While caffeine removal efficiency was found to range between $96-99 \%$ regardless of the hazardous events, effluent caffeine concentration increased significantly (from around 100 up to $2500 \mathrm{ng} / \mathrm{L}$ ) immediately after hazardous events occurred. Effluent concentration returned to baseline within $24 \mathrm{~h}$ in case of aeration failure, but a full recovery was not achieved even within $72 \mathrm{~h}$ for the other events. It was a similar outcome for ibuprofen which had a concentration of $5-15 \mu \mathrm{g} / \mathrm{L}$ in the influent during the observation period. While over $90 \%$ removal was consistently achieved, all hazardous events caused significant increase in effluent ibuprofen concentration. For example, in case of ammonia shock, effluent ibuprofen concentration increased from 14 $\pm 3 \mathrm{ng} / \mathrm{L}$ (before adding ammonia) to $215 \pm 13 \mathrm{ng} / \mathrm{L}$ within $1 \mathrm{~h}$ of ammonia addition. By contrast, caffeine and ibuprofen were only slightly affected by ammonia shock or power failure in a previous MBR study (Trinh, 2013), but this discrepancy may be explained by the fact that the influent TrOC concentrations in that study were lower.

Naproxen removal was observed to gradually reduce from $98 \%$ to $77 \%$ within $24 \mathrm{~h}$ of ammonia shock; however, the removal had mostly recovered within $72 \mathrm{~h}$ (Figure 3). A similar outcome for naproxen removal was observed with the other hazardous events. Compared to the study of Trinh (2013), a greater impact on naproxen removal was observed in the current study, possibly because a higher ammonia shock dose (260 vs. $140 \mathrm{mg} \mathrm{NH}{ }_{4}{ }^{+}-\mathrm{N} / \mathrm{g}$ MLSS) and a longer power failure period (18 vs. $2 \mathrm{~h}$ ) were applied here. Trimethoprim has been reported to be degraded only by slow-growing bacteria such as nitrifiers (Pérez et al., 2005) that are known to be more sensitive to environmental factors. Indeed, a wide variation (0-90\%) in trimethoprim removal by 
activated sludge treatment has been reported in the literature (Tadkaew et al., 2011). In the current study, trimethoprim removal dropped from around $60 \%$ to no removal within $1 \mathrm{~h}$ of ammonia shock, although a complete recovery of removal was observed within 72 h. A similar impact was observed after bleach shock, while a slight fluctuation in removal was found for aeration and power failure events. Gemfibrozil removal has been previously correlated to $\mathrm{NH}_{4}{ }^{+}-\mathrm{N}$ removal (Phan et al., 2015). Indeed Trinh (2013), reported significant impact of ammonia shock on gemfibrozil removal. In the current study, gemfibrozil was detected in influent only during aeration failure and ammonia shock experiments, and, unaffected by the hazardous events, it was completely removed. The discrepancy with the study of Trinh (2013) may be explained by the significantly lower influent gemfibrozil concentration in the current study $(<15$ $\mathrm{ng} / \mathrm{L} v s .1 \mu \mathrm{g} / \mathrm{L})$.

Influent sulfamethoxazole concentration during the current study varied from 0.02 (ammonia shock) to $6.7 \mu \mathrm{g} / \mathrm{L}$ (aeration failure), which led to significant variation in removal (20-69\%) even without occurrence of the hazardous events (Figure 3), suggesting kinetic limitations. This is consistent with the high variability (50-90\%) in sulfamethoxazole removal reported in the literature (Tadkaew et al., 2011). Furthermore, consistent with another study (Trinh, 2013), sulfamethoxazole removal decreased from 69 to $35 \%$ within $1 \mathrm{~h}$ of ammonia shock. However, interestingly, $24 \mathrm{~h}$ after applying the ammonia shock, the removal increased to around $80 \%$. No other hazardous event studies (CAS or MBR) have reported such a phenomenon, but drawing on the report of Gulde et al. (2014) regarding increased biotransformation rate of cationic-neutral TrOCs such as sulfamethoxazole due to $\mathrm{pH}$ increase from 7 to 8 , the observation made in this study may also be attributed to the increased $\mathrm{pH}$ of the bioreactors due to ammonia addition. Additionally, the improved removal of sulfamethoxazole (20 vs. 75\%) after bleach shock may be attributed to the oxidative degradation of this TrOC by chlorine. Gao et al. (2014) reported effective removal over an initial sulfamethoxazole concentration range of $0.05-5 \mathrm{mg} / \mathrm{L}$ after addition of a chlorine dose of $2 \mathrm{mg} / \mathrm{L}$, which is well below that applied in the current study. Similarly, the improved aqueous triclosan removal during bleach shock may be attributed to the formation of chlorinated triclosan derivatives (Buth et al., 2011), and not necessarily breakdown to smaller metabolites.

\subsubsection{TrOC concentration in sludge}

Of the 45 monitored TrOCs, nine pharmaceuticals were detected in sludge at concentrations over the detection limit during the monitoring period (Figure 4). All significantly hydrophobic TrOCs (i.e., compounds having $\log \mathrm{D}>3$ ), except triclosan and triclocarban, were consistently well removed from the aqueous phase by the MBR irrespective of the hazardous events (Figure 3). Furthermore, these compounds were not detected in sludge, which confirms their biodegradation. Conversely, triclosan (140 $940 \mathrm{ng} / \mathrm{g}$ MLSS) and triclocarban (960 - $1500 \mathrm{ng} / \mathrm{g}$ MLSS) were detected in sludge at concentrations much higher than all other TrOCs (5 - $450 \mathrm{ng} / \mathrm{g}$ MLSS) (Figure 4). In fact the accumulated mass of triclosan and triclocarban on sludge accounted for up to 14 and over $95 \%$, respectively, of their influent load. This suggests that triclocarban underwent insignificant biotransformation. Similar observations were reported by Trinh (2013). Sludge-adsorption data for the aeration failure event was unavailable, however, 
no significant impact of the toxic shocks or the power failure event on triclocarban adsorption was observed. On the other hand, triclosan concentration in both aqueous and sludge phases increased following the ammonia shock (Figure 4), indicating that triclosan biotransformation was significantly affected by ammonia shock.

Several hydrophilic TrOCs, whose aqueous phase removal was susceptible to one or more hazardous events, were also detected in sludge (Figure 4). This is consistent with previous reports that TrOC accumulation in sludge may depend on their inherent biodegradability and concentration in wastewater in addition to adsorption capacity (Wijekoon et al., 2013), and thus hydrophilic TrOCs which are resistant and/or occur at high concentrations in wastewater can also accumulate in sludge. Hazardous events appeared to influence the sludge concentration of these hydrophilic compounds to some extent but a clear relationship between concentration in sludge and their aqueous phase removal could not be established, indicating that their removal was controlled more by biodegradation. For example, within $3 \mathrm{~h}$ of ammonia shock, the concentration of paracetamol increased from 110 to $450 \mathrm{ng} / \mathrm{g}$ MLSS, but was then reduced to $15 \mathrm{ng} / \mathrm{g}$ MLSS within $24 \mathrm{~h}$. However, the effluent concentration of paracetamol was always below the detection limit following the ammonia shock. Consistent with the current study, Trinh (2013) observed no clear impact of hazardous events including ammonia shock and power failure on TrOC adsorption to MLSS.

\subsection{Impact on effluent estrogenicity and toxicity}

There was a significant variation in estrogenicity (Figure 5) and toxicity (Table 1) of the influent between the various simulated hazardous events. For example, higher estrogenicity was measured in influent during the power failure simulation compared to the aeration failure experiment. This variation was also reflected in chemical analysis results, with greatly higher influent concentration of estrogen hormones (17 $\beta$-estradiol, estrone and estriol) during the power failure simulation compared to those detected in influent during the aeration failure experiment. Similarly, the extremely low influent toxicity ( $0.52 \mathrm{rTU}$ compared to $44-79 \mathrm{rTU}$ in other events) during the aeration failure test is reflected in the low influent COD (about $70-75 \%$ less than in the other events) during that period. However, significant reduction of both estrogenicity (Figure 5) and toxicity (Table 1) was achieved following MBR treatment irrespective of the occurrence of any simulated hazardous events. This was again in line with the stable removal of estrogenic TrOCs during the hazardous events established by chemical analysis (Figure 3). An estrogenic activity of $1 \mathrm{ng} / \mathrm{L}$ EEQ is commonly accepted as unlikely to cause significant endocrine effects in exposed aquatic biota (Leusch et al., 2014; Scott et al., 2014), and the MBR effluent estrogenicity in this study was consistently below this threshold value even during hazardous events.

Anti-estrogenic activity was detected in influent during the ammonia shock simulation, and in MBR effluent $24 \mathrm{~h}$ after the ammonia and bleach shock (Figure 5). Although much less is known about the significance of anti-estrogenic activity in wastewater, both estrogenic and anti-estrogenic activity can lead to endocrine disruption in aquatic organisms (Pike et al., 2001). The appearance of anti-estrogenic activity during bleach shock appears to indicate the formation of anti-estrogenic by-products, possibly the result of chlorination of aromatic amino acid and humic/fulvic acid components of 
wastewater matrix (Tang et al., 2014). Ammonia shock has been reported to cause abiotic nitration of estrogens in wastewater treatment in case of high influent $\mathrm{NH}_{4}{ }^{-} \mathrm{N}$ concentration $(>200 \mathrm{mg} / \mathrm{L})$ or in process conditions that prevent conversion of $\mathrm{NO}_{2}{ }^{-} \mathrm{N}$ to $\mathrm{NO}_{3}{ }^{-}-\mathrm{N}$ (Gaulke et al., 2008). The nitrated forms of these chemicals show lower estrogenic activity than the parent compounds; however, their anti-estrogenic activity has not been established (Sun et al., 2012). Nevertheless, this is the first report on effluent estrogenicity and toxicity following simulated hazardous events, and results from this study confirm that MBRs can efficiently reduce estrogenicity and toxicity from wastewater, but toxic shocks such as that from ammonia or bleach could temporarily increase the endocrine activity of effluent after significant process disturbances.

\subsection{Impact on membrane fouling}

Hazardous events such as chemical shock can alter sludge settling and dewatering properties and consequently affect filterability of the mixed liquor. For example, exchange of monovalent ammonium with divalent cations in sludge can result in weaker and fragile flocs (Novak, 2001; Semblante et al., 2014), or elevated release of soluble microbial product and extracellular polymeric substance into the mixed liquor can occur upon exposure to toxic shocks (Hai et al., 2012b; Kimura et al., 2014) - all of which can result in aggravated membrane fouling. In this study, slight but discernible increase in TMP (up to $5 \mathrm{kPa}$ ) was observed during the simulated hazardous events (Supplementary Data Figure S12). This is in agreement with previous reports regarding the impact of power failure and ammonia shock (Trinh et al., 2015) and bleach shock (Knops, 2010) on membrane fouling. However, the extent of membrane fouling may be governed by the chemical shock-dose and particularly the applied membrane flux. In this context, it is noteworthy that, compared to Trinh et al. (2015) and Knops (2010), a significantly higher ammonia (140 vs. $260 \mathrm{mg} \mathrm{NH}_{4}{ }^{+}-\mathrm{N} / \mathrm{g}$ MLSS) and bleach dose (3.3 vs. $13 \mathrm{mg} \mathrm{Cl}_{2}$ /g MLSS), respectively was applied in the current study. By contrast, the applied membrane flux $\left(1.2 \mathrm{~L} / \mathrm{m}^{2} . \mathrm{h}\right)$ in the current study was only $5-10 \%$ of that applied by Trinh et al. (2015) and Knops (2010). Thus the results reported here do not necessarily imply that hazardous events will always have minor impacts on membrane hydraulic performance. Indeed, despite seemingly moderate impact on TMP during MBR operation, heightened filtration resistance was recorded during processing (for analysis) of bleach-shock samples via high-flux filtration, indicating the role of flux on membrane fouling during hazardous events.

\section{Conclusions}

Ammonia shock showed the greatest impact that led to an immediate loss of TOC, TN, $\mathrm{NH}_{4}{ }^{+}-\mathrm{N}$, and $\mathrm{PO}_{4}{ }^{3-}-\mathrm{P}$ removal capacity. TOC removal recovery was swift $(72 \mathrm{~h})$, while that of TN took over two weeks. Other hazardous events induced less severe and brief impacts. Removal of a number of TrOCs which are resistant and/or occur at high concentrations in wastewater were affected. The MBR effectively reduced estrogenicity and toxicity from wastewater, but chemical shocks temporarily increased the effluent endocrine activity. Additionally, hazardous events may exacerbate membrane fouling depending on the dose of chemical shock and the membrane flux. 


\section{Acknowledgements}

Hop V. Phan thanks the University of Wollongong (Australia) and the Thanh Hoa provincial government (Viet Nam) for a joint PhD scholarship. Thanks are due to Zenon Environmental Inc., Canada for supplying the membrane module. University of Wollongong is gratefully acknowledged for the provision of a Research Partnership Grant with industry support from Shoalhaven Water (NSW). The authors thank Luke Elliott for his kind cooperation throughout the study at the Kangaroo Valley MBR plant.

\section{References}

[1] Alexander, J.T., Hai, F.I., Al-aboud, T.M. 2012. Chemical coagulation-based processes for trace organic contaminant removal: Current state and future potential. Journal of Environmental Management, 111, 195-207.

[2] Baldwin, D.D., Campbell, C.E. 2001. Short-term effects of low pH on the microfauna of an activated sludge wastewater treatment system. Water Quality Research Journal of Canada, 36, 519-535.

[3] Bartram, J., Corrales, L., Davison, A., Deere, D., Drury, D., Gordon, B., Howard, G., Rinehold, A., Stevens, M. 2009. Water safety plan manual: step-by-step risk management for drinking-water suppliers, (Ed.) World Health Organization. Geneva, Switzerland.

[4] Bodík, I., Gašpariková, E., Dančová, L., Kalina, A., Hutňan, M., Drtil, M. 2008. Influence of disinfectants on domestic wastewater treatment plant performance. Bioresource Technology, 99, 532-539.

[5] Burgess, J.E., Colliver, B.B., Stuetz, R.M., Stephenson, T. 2002. Dinitrogen oxide production by a mixed culture of nitrifying bacteria during ammonia shock loading and aeration failure. Journal of Industrial Microbiology and Biotechnology, 29, 309-313.

[6] Buth, J.M., Ross, M.R., McNeill, K., Arnold, W.A. 2011. Removal and formation of chlorinated triclosan derivatives in wastewater treatment plants using chlorine and UV disinfection. Chemosphere, 84, 1238-1243.

[7] Ding, Y.H., Ren, H.Q., Wang, Q. 2014. Inhibition of the activities of activated sludge in a sequencing batch reactor by high-strength ammonium nitrogen. Desalination and Water Treatment, 52, 2792-2798.

[8] Eaton, A.D., Clescerl, L.S., Rice, E.W., Greenberg, A.E. 2005. Standard Methods for Examination of Water \& Wastewater. 21st ed. American Public Health Association, Washington, D. C.

[9] Escher, B.I., Allinson, M., Altenburger, R., Bain, P.A., Balaguer, P., Busch, W., Crago, J., Denslow, N.D., Dopp, E., Hilscherova, K., Humpage, A.R., Kumar, A., Grimaldi, M., Jayasinghe, B.S., Jarosova, B., Jia, A., Makarov, S., Maruya, K.A., Medvedev, A., Mehinto, A.C., Mendez, J.E., Poulsen, A., Prochazka, E., Richard, J., Schifferli, A., Schlenk, D., Scholz, S., Shiraishi, F., Snyder, S., Su, G., Tang, J.Y.M., Burg, B.v.d., Linden, S.C.v.d., Werner, I., Westerheide, S.D., Wong, C.K.C., Yang, M., Yeung, B.H.Y., Zhang, X., Leusch, F.D.L. 2014. Benchmarking organic micropollutants in wastewater, recycled water and drinking water with in vitro bioassays. Environmental Science \& Technology, $48,1940-1956$. 
[10] Gao, S., Zhao, Z., Xu, Y., Tian, J., Qi, H., Lin, W., Cui, F. 2014. Oxidation of sulfamethoxazole (SMX) by chlorine, ozone and permanganate-A comparative study. Journal of Hazardous Materials, 274, 258-269.

[11] Gaulke, L.S., Strand, S.E., Kalhorn, T.F., Stensel, H.D. 2008. 17 $\alpha$-ethinylestradiol transformation via abiotic nitration in the presence of ammonia oxidizing bacteria. Environmental Science and Technology, 42, 7622-7627.

[12] Gulde, R., Helbling, D.E., Scheidegger, A., Fenner, K. 2014. PH-dependent biotransformation of ionizable organic micropollutants in activated sludge. Environmental Science and Technology, 48, 13760-13768.

[13] Hai, F.I., Modin, O., Yamamoto, K., Fukushi, K., Nakajima, F., Nghiem, L.D. 2012a. Pesticide removal by a mixed culture of bacteria and white-rot fungi. Journal of the Taiwan Institute of Chemical Engineers, 43, 459-462.

[14] Hai, F.I., Nghiem, L.D., Khan, S.J., Price, W.E., Yamamoto, K. 2014a. Wastewater reuse: removal of emerging trace organic contaminants. in: Membrane Biological Reactors: Theory, Modeling, Design, Management and Applications to Wastewater Reuse, (Eds.) F.I. Hai, K. Yamamoto, C.-H. Lee, IWA publishing, UK pp. 163-203.

[15] Hai, F.I., Yamamoto, K., Lee, C.-H. 2014b. Membrane Biological Reactors: Theory, Modeling, Design, Management and Applications to Wastewater Reuse. IWA Publishing, London (ISBN: 9781780400655).

[16] Hai, F.I., Yamamoto, K., Nakajima, F., Fukushi, K. 2012b. Application of a GACcoated hollow fiber module to couple enzymatic degradation of dye on membrane to whole cell biodegradation within a membrane bioreactor. Journal of Membrane Science, 389, 67-75.

[17] Kimura, K., Meng, F., Chang, I.-S., Lee, C.-H. 2014. Monitoring, characterization and control of membrane biofouling in MBR. in: Membrane Biological Reactors: Theory, Modeling, Design, Management and Applications to Wastewater Reuse, (Eds.) F.I. Hai, K. Yamamoto, C.-H. Lee, IWA publishing, UK pp. 97 - 127.

[18] Knops, G.J.A. 2010. Impact of Chemical Shock Loads on a Membrane Bioreactor for Urban Water Reuse. PhD thesis, Centre for Water Science, School of Applied Sciences, Cranfield University, UK.

[19] Leusch, F.D.L., Khan, S.J., Gagnon, M.M., Quayle, P., Trinh, T., Coleman, H., Rawson, C., Chapman, H.F., Blair, P., Nice, H., Reitsema, T. 2014. Assessment of wastewater and recycled water quality: A comparison of lines of evidence from in vitro, in vivo and chemical analyses. Water Research, 50, 420-431.

[20] Novak, J.T. 2001. The effect of the ammonium ion on activated-sludge settling properties. Water Environment Research, 73, 409-414.

[21] Pérez, S., Eichhorn, P., Aga, D.S. 2005. Evaluating the biodegradability of sulfamethazine, sulfamethoxazole, sulfathiazole, and trimethoprim at different stages of sewage treatment. Environmental Toxicology and Chemistry, 24, 1361-1367.

[22] Phan, H.V., Hai, F.I., Kang, J., Dam, H.K., Zhang, R., Price, W.E., Broeckmann, A., Nghiem, L.D. 2014. Simultaneous nitrification/denitrification and trace organic contaminant (TrOC) removal by an anoxic-aerobic membrane bioreactor (MBR). Bioresource Technology, 165, 96-104.

[23] Phan, H.V., Hai, F.I., McDonald, J.A., Khan, S.J., Zhang, R., Price, W.E., Broeckmann, A., Nghiem, L.D. 2015. Nutrient and trace organic contaminant 
removal from wastewater of a resort town: Comparison between a pilot and a full scale membrane bioreactor. International Biodeterioration \& Biodegradation (DOI: http://dx.doi.org/10.1016/j.ibiod.2015.02.010).

[24] Pike, A.C.W., Brzozowski, A.M., Walton, J., Hubbard, R.E., Thorsell, A.G., Li, Y.L., Gustafsson, J.A., Carlquist, M. 2001. Structural insights into the mode of action of a pure antiestrogen. Structure, 9, 145-153.

[25] Scott, P., Bartkow, M., Blockwell, S., Coleman, H., Khan, S., Lim, R., McDonald, J., Nice, H., Nugegoda, D., Pettigrove, V., Tremblay, L., Warne, M.J., Leusch, F.L. 2014. An assessment of endocrine activity in Australian rivers using chemical and in vitro analyses. Environmental Science and Pollution Research, 21, 12951-12967.

[26] Semblante, G.U., Hai, F.I., Ngo, H.H., Guo, W., You, S.-J., Price, W.E., Nghiem, L.D. 2014. Sludge cycling between aerobic, anoxic and anaerobic regimes to reduce sludge production during wastewater treatment: Performance, mechanisms, and implications. Bioresource Technology, 155, 395-409.

[27] Sun, Q., Li, Y., Chou, P.H., Peng, P.Y., Yu, C.P. 2012. Transformation of bisphenol $\mathrm{A}$ and alkylphenols by ammonia-oxidizing bacteria through nitration. Environmental Science and Technology, 46, 4442-4448.

[28] Tadkaew, N., Hai, F.I., McDonald, J.A., Khan, S.J., Nghiem, L.D. 2011. Removal of trace organics by MBR treatment: The role of molecular properties. Water Res., 45, 2439-2451.

[29] Tang, X., Wu, Q.Y., Du, Y., Yang, Y., Hu, H.Y. 2014. Anti-estrogenic activity formation potential assessment and precursor analysis in reclaimed water during chlorination. Water Research, 48, 490-497.

[30] Trinh, T., Branch, A., Le-Clech, P., Hambly, A.C., Carvajal, G., Coleman, H.M., Stuetz, R.M., Drewes, J.E., Khan, S.J. 2015. Hazardous events in membrane bioreactors - impacts on key operational and bulk water quality parameters. Journal of Membrane Science (DOI:http://dx.doi.org/10.1016/j.memsci.2015.03.003).

[31] Trinh, T., Branch, A., van den Akker, B., Le-Clech, P., Drewes, J.E., Khan, S.J. 2014. Impacts of hazardous events on performance of membrane bioreactors. in: Membrane Biological Reactors: Theory, Modeling, Design, Management and Applications to Wastewater Reuse, (Eds.) F.I. Hai, K. Yamamoto, C.-H. Lee, IWA publishing, UK pp. 207-221.

[32] Trinh, T. 2013. Process robustness and impacts of hazardous events on membrane bioreactor performance. PhD thesis, Cilvil \& Environmental Engineering, Faculty of Engineering, University of New South Wales. Sydney, Australia.

[33] van de Merwe, J.P., Leusch, F.D.L. 2015. A sensitive and high throughput bacterial luminescence assay for assessing aquatic toxicity - the BLT-Screen. Environmental Science: Processes \& Impacts 17, 947-955.

[34] Villain, M., Clouzot, L., Guibaud, G., Marrot, B. 2013. Impact of oxygen cut off and starvation conditions on biological activity and physico-chemical properties of activated sludge. Environmental Technology (United Kingdom), 34, 901-910.

[35] Wijekoon, K.C., Hai, F.I., Kang, J., Price, W.E., Guo, W., Ngo, H.H., Nghiem, L.D. 2013. The fate of pharmaceuticals, steroid hormones, phytoestrogens, UVfilters and pesticides during MBR treatment. Bioresource Technology, 144, 247254. 


\section{LIST OF TABLES}

Table 1: Toxicity in influent and effluent of the MBR, expressed as relative toxicy unit (rTU). Effluent samples were collected immediately before hazardous events $(0 \mathrm{~h})$ and at 3 and $24 \mathrm{~h}$ after resuming normal operation (following aeration or power failure) or application of shock loading. Values indicate average \pm standard deviation $(n=2)$.

\begin{tabular}{|l|c|c|c|c|}
\hline Sample & \multicolumn{4}{|c|}{ Toxicity (rTU) } \\
\hline & Aeration failure & Power failure & Ammonia shock & Bleach shock \\
\hline Feed & $0.52^{\mathrm{a}}$ & $44^{\mathrm{a}}$ & $79^{\mathrm{a}}$ & -- \\
\hline Effluent $(0 \mathrm{~h})$ & $0.19 \pm 0.01$ & $0.27 \pm 0.02$ & $0.14 \pm 0.02$ & $0.15 \pm 0.01$ \\
\hline Effluent $(3 \mathrm{~h})$ & -- & $0.20 \pm 0.04$ & $0.22 \pm 0.02$ & $0.35 \pm 0.03$ \\
\hline Effluent $(24 \mathrm{~h})$ & $0.22^{\mathrm{a}}$ & $0.21 \pm 0.01$ & $0.23 \pm 0.04$ & $0.34^{\mathrm{a}}$ \\
\hline
\end{tabular}

${ }^{a}$ Single samples 


\section{LIST OF FIGURES}

Figure 1: Impact of ammonia shock on TOC, $\mathrm{COD}$ and $\mathrm{TN}$ removal performance by the MBR. Addition of $\mathrm{NH}_{4} \mathrm{HCO}_{3}$ to achieve a $\mathrm{NH}_{4}{ }^{+}-\mathrm{N}$ concentration of $1000 \mathrm{mg} / \mathrm{L}$ caused an instantaneous additional TOC and TN load of 670 and $780 \mathrm{mg} / \mathrm{L}$, respectively.

Figure 2: Impact of ammonia shock on the formation of $\mathrm{NO}_{\mathrm{x}}{ }^{-} \mathrm{N}$ and the removal performance of $\mathrm{NH}_{4}{ }^{+}-\mathrm{N}$ and $\mathrm{PO}_{4}{ }^{3-}-\mathrm{P}$ by the MBR.

Figure 3: Impact of hazardous events (a. aeration failure, b. power failure, c. ammonia shock, and d. bleach shock) on the effluent concentrations of 26 TrOCs which were detected beyond detection limit in influent during at least one of the hazardous events (Note: "*" indicates that the concentration of this TrOC in effluent was below detection limit in that event; "\#” indicates that this TrOC remained undetected in both influent and effluent in that specific event). Error bars indicate the standard deviation from triplicate samples.

Figure 4: Concentration of nine TrOCs detected over detection limit in sludge before ( 0 h) and at 3 and $24 \mathrm{~h}$ after the hazardous events (power failure, ammonia shock and bleach shock). Data plotted are average of duplicate samples.

Figure 5: Estrogenic (17 $\beta$-estradiol equivalent, EEQ) and anti-estrogenic (Tamoxifen equivalent, TMXEQ) activities measured in influent and effluent of the MBR during hazardous event experiments. Effluent samples were collected immediately before hazardous events $(0 \mathrm{~h})$ and at 3 and $24 \mathrm{~h}$ after resuming normal operation (following aeration or power failure) or application of shock loading. Where applicable, error bars represent the standard deviation from duplicate samples. 


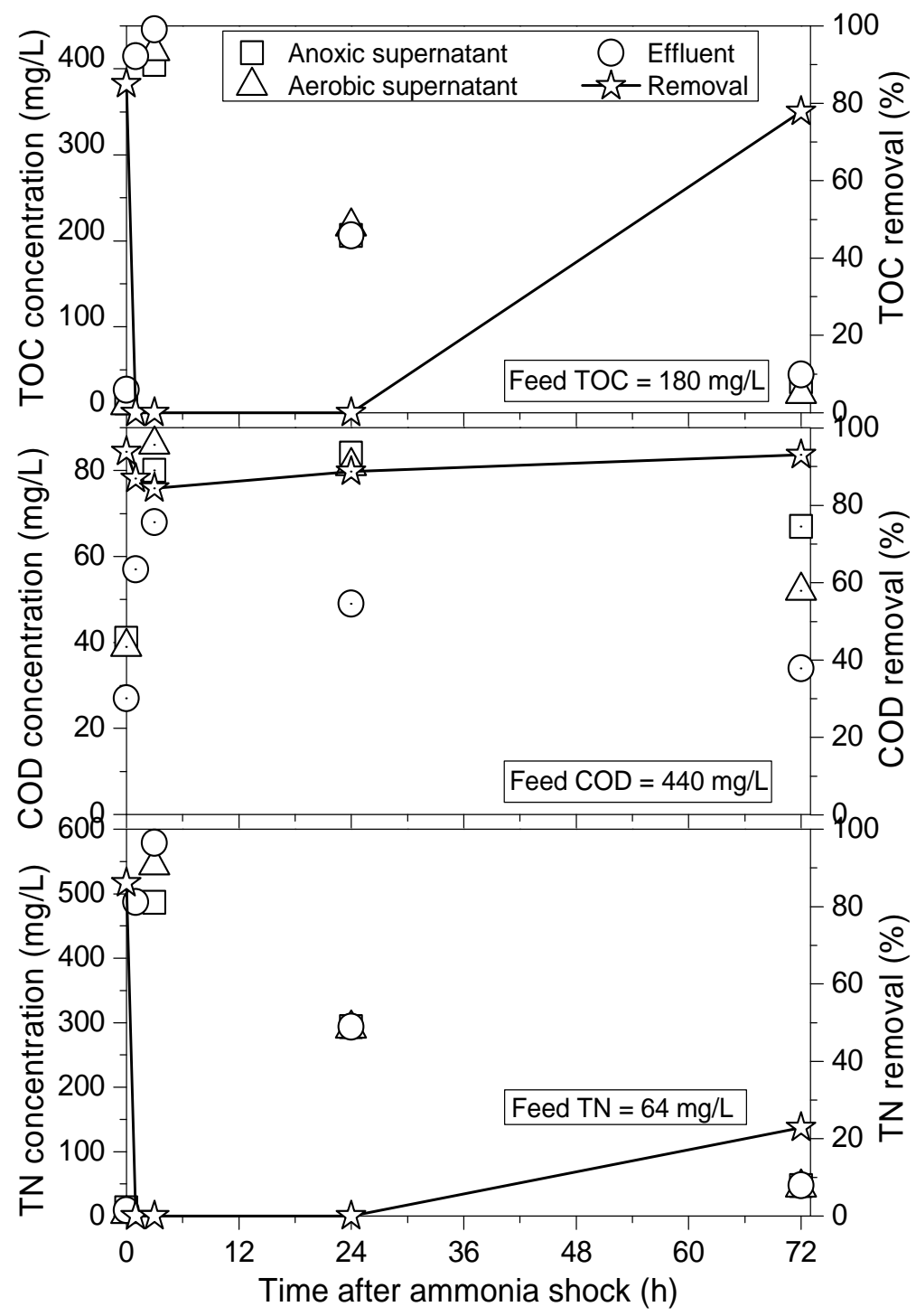

Figure 1 


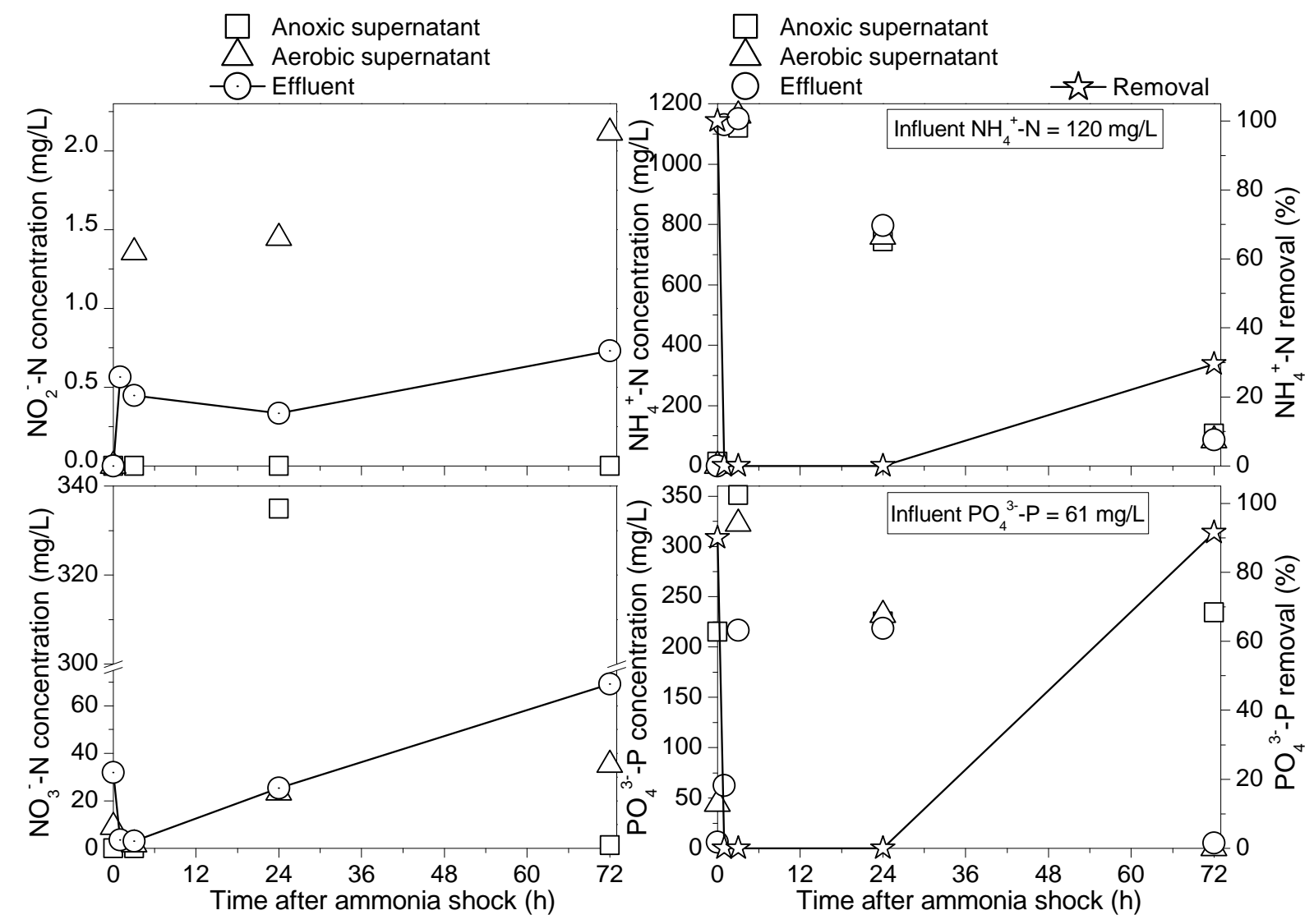

Figure 2 

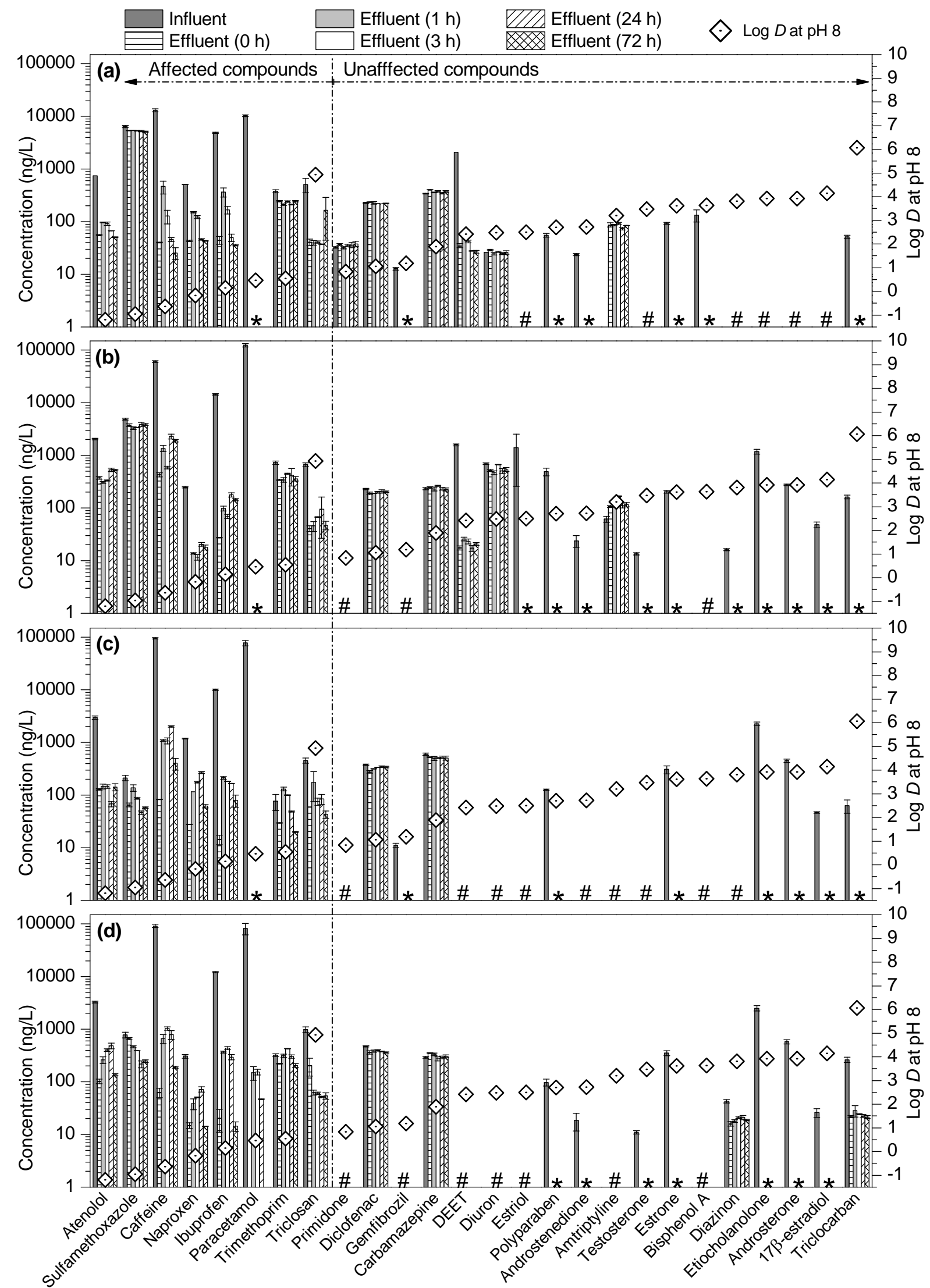


\section{Figure 3}

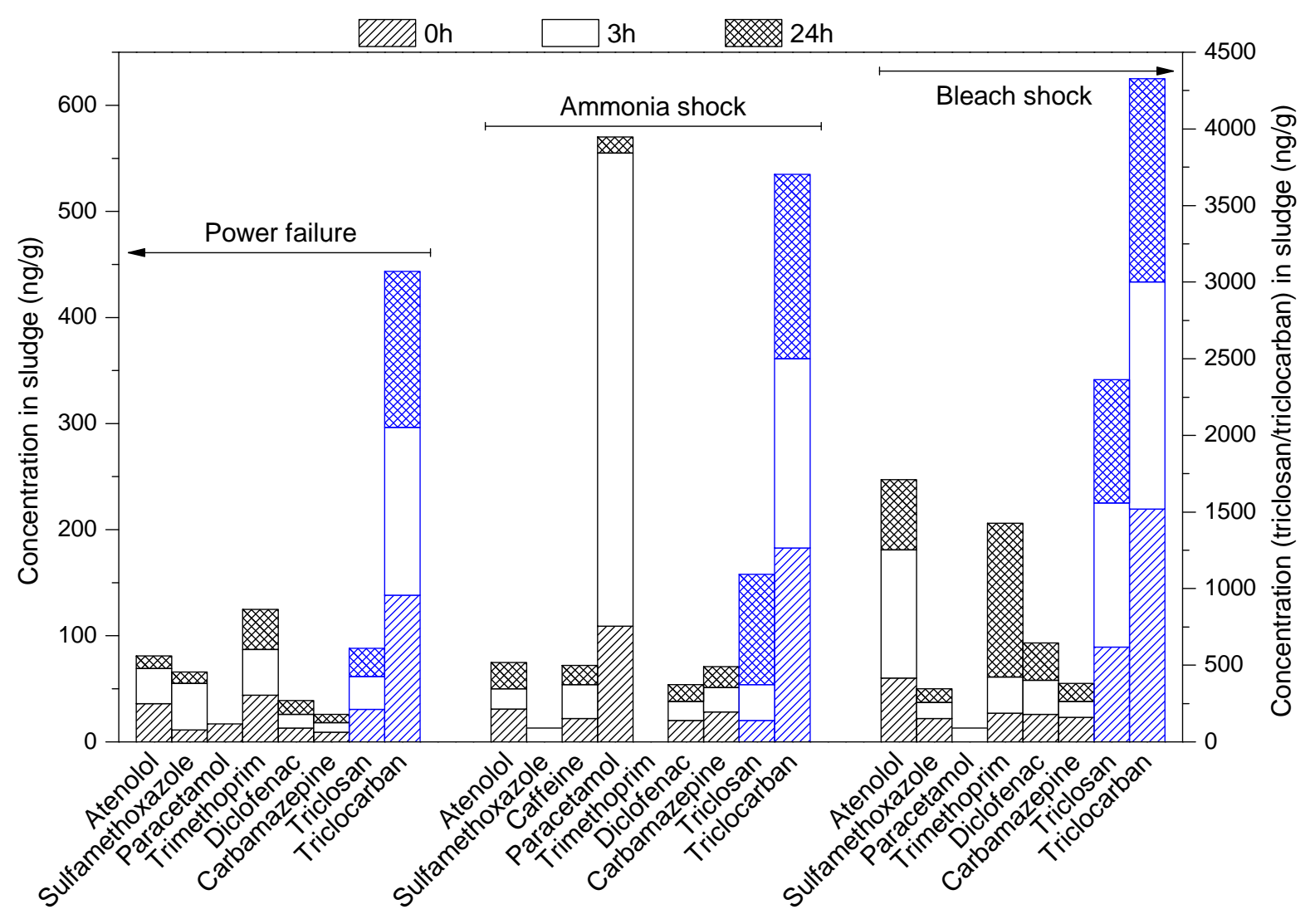

Figure 4 

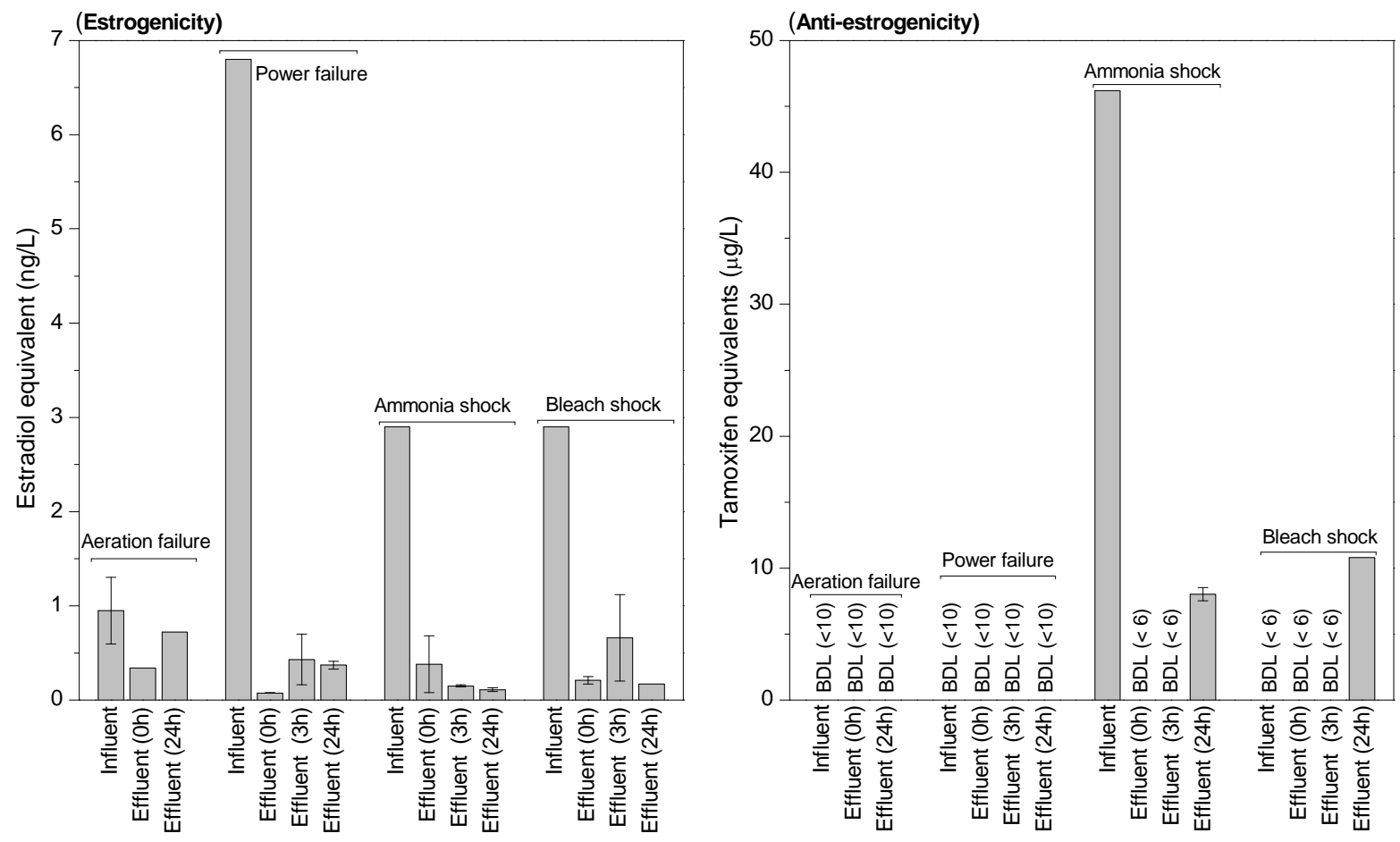

Figure 5 


\section{Supplementary Data}

Impact of hazardous events on the removal of nutrients and trace organic contaminants by an anoxic-aerobic membrane bioreactor receiving real wastewater

Hop V. Phan ${ }^{\mathrm{a}}$, Faisal I. Hai ${ }^{\mathrm{a}^{*}}$, James A. McDonald ${ }^{\mathrm{b}}$, Stuart J. Khan ${ }^{\mathrm{b}}$, Jason P. van de Merwe ${ }^{\mathrm{c}}$, Frederic D. L. Leusch ${ }^{\mathrm{c}}$, Ren Zhang ${ }^{\mathrm{d}}$, William E. Price ${ }^{\mathrm{e}}$, Andreas Broeckmann ${ }^{\mathrm{f}}$, Long D. Nghiem $^{\mathrm{a}}$

${ }^{a}$ Strategic Water Infrastructure Lab, School of Civil, Mining and Environmental Engineering, University of Wollongong, NSW 2522, Australia.

${ }^{\mathrm{b}}$ School of Civil and Environmental Engineering, University of New South Wales, NSW 2052, Australia.

${ }^{\mathrm{c}}$ Smart Water Research Centre, School of Environment, Griffith University, QLD 4222, Australia

${ }^{\mathrm{d}}$ Molecular Biology Lab, School of Biological Sciences, University of Wollongong, NSW 2522, Australia.

'Strategic Water Infrastructure Lab, School of Chemistry, University of Wollongong, NSW 2522, Australia.

${ }^{\mathrm{f}} \mathrm{GHD}$, NSW 2541, Australia.

${ }^{*}$ Corresponding author: Faisal I. Hai (E-mail: faisal@uow.edu.au; Phone: +61-2-4221-3054) 
Table S2: List of 45 monitored trace organic contaminants (TrOCs) and their detection limits

\begin{tabular}{|c|c|}
\hline Compounds & $\begin{array}{c}\text { Detection limit } \\
\text { (ng/L) }\end{array}$ \\
\hline
\end{tabular}

Pharmaceutical and personal care products (PPCPs)

\begin{tabular}{|l|c|}
\hline Atenolol & 5 \\
\hline Paracetamol & 5 \\
\hline Sulfamethoxazole & 5 \\
\hline Caffeine & 10 \\
\hline
\end{tabular}

\begin{tabular}{|l|c|}
\hline Trimethoprim & 5 \\
\hline Dilantin & 5 \\
\hline Carbamazepine & 5 \\
\hline
\end{tabular}

\begin{tabular}{|l|l|}
\hline Carbamazepine & 5 \\
\hline Fluoxetine & 5 \\
\hline Enalapril & 5 \\
\hline Risperidone & 5 \\
\hline
\end{tabular}

\begin{tabular}{|l|l|}
\hline Risperidone & 5 \\
\hline Omeprazole & 5 \\
\hline Clozapine & 5 \\
\hline Amptyline & 5 \\
\hline
\end{tabular}

\begin{tabular}{|l|l|}
\hline Amtriptyline & 5 \\
\hline DEET & 5 \\
\hline Primidone & 5 \\
\hline
\end{tabular}

\begin{tabular}{|l|l|}
\hline Verapamil & 5 \\
\hline Triamterene & 5 \\
\hline Meprobamate & 5 \\
\hline
\end{tabular}

\begin{tabular}{|l|c|}
\hline Hydroxyzine & 5 \\
\hline Diazepam & 5 \\
\hline Ketoprofen & 5 \\
\hline Naproxen & 5 \\
\hline Ibuprofen & 5 \\
\hline Gemfibrozil & 5 \\
\hline Triclosan & 5 \\
\hline Diclofenac & 5 \\
\hline Triclocarban & 10 \\
\hline
\end{tabular}

\begin{tabular}{|l|c|}
\hline Industrial chemicals \\
\hline Polyparaben & 10 \\
\hline TCEP & 10 \\
\hline Bisphenol A & 20 \\
\hline 4-n-nonylphenol & 5 \\
\hline Steroid hormones \\
\hline Estriol \\
\hline Androstendione & 10 \\
\hline Testosterone & 5 \\
\hline Estrone & 5 \\
\hline
\end{tabular}




\begin{tabular}{|l|c|}
\hline $17 \beta$-estradiol & 5 \\
\hline $17 \alpha$-estradiol & 5 \\
\hline Etiocholanolone & 5 \\
\hline Androsterone & 5 \\
\hline Pesticides & \multicolumn{2}{|l|}{} \\
\hline Diazinon & 5 \\
\hline Simazine & 5 \\
\hline Atrazine & 5 \\
\hline Linuron & 5 \\
\hline Phenylphenol & 20 \\
\hline Diuron & 10 \\
\hline
\end{tabular}



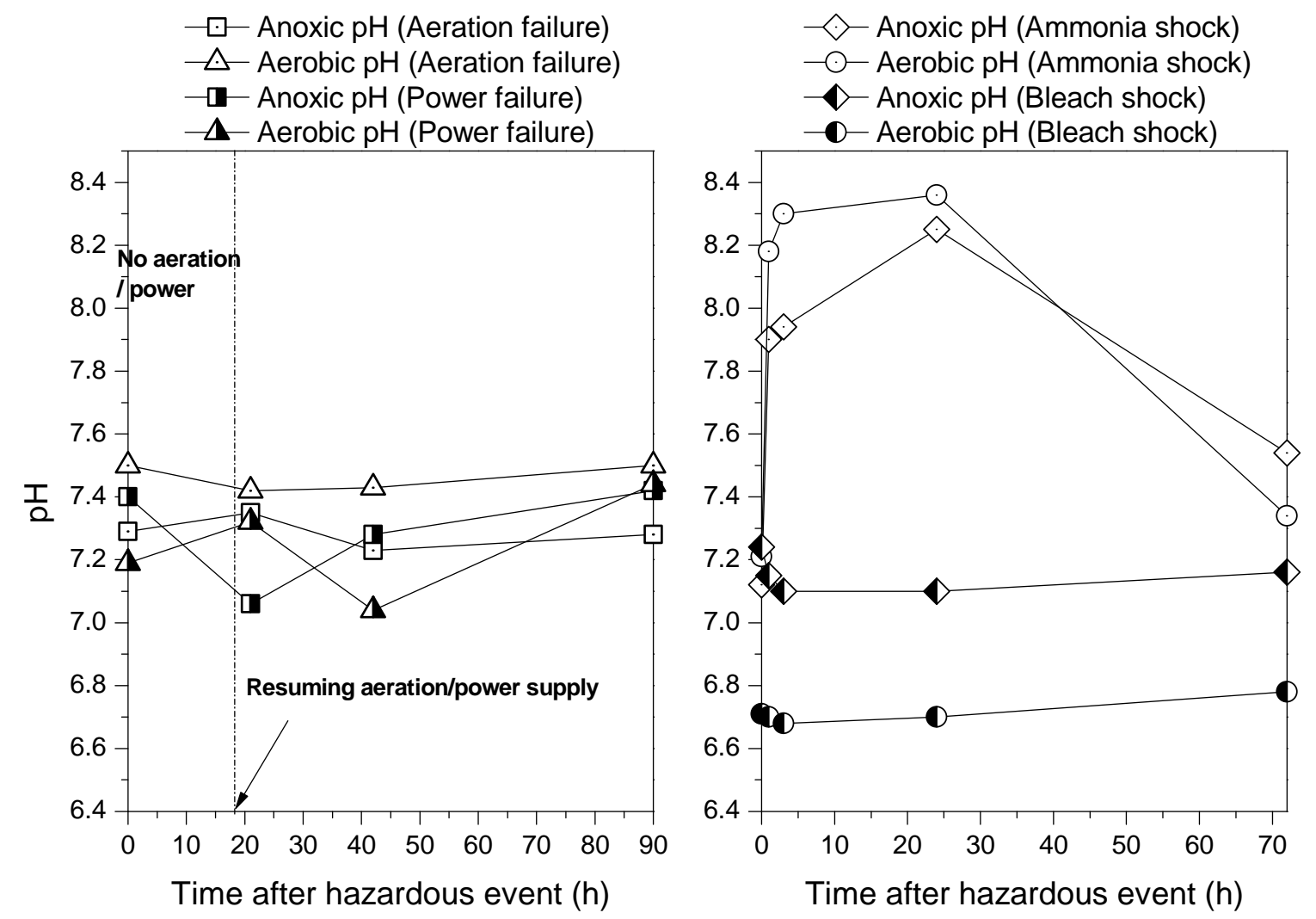

Figure S2: Impact of hazardous events on mixed liquor $\mathrm{pH}$ in anoxic and aerobic bioreactors of the MBR. 


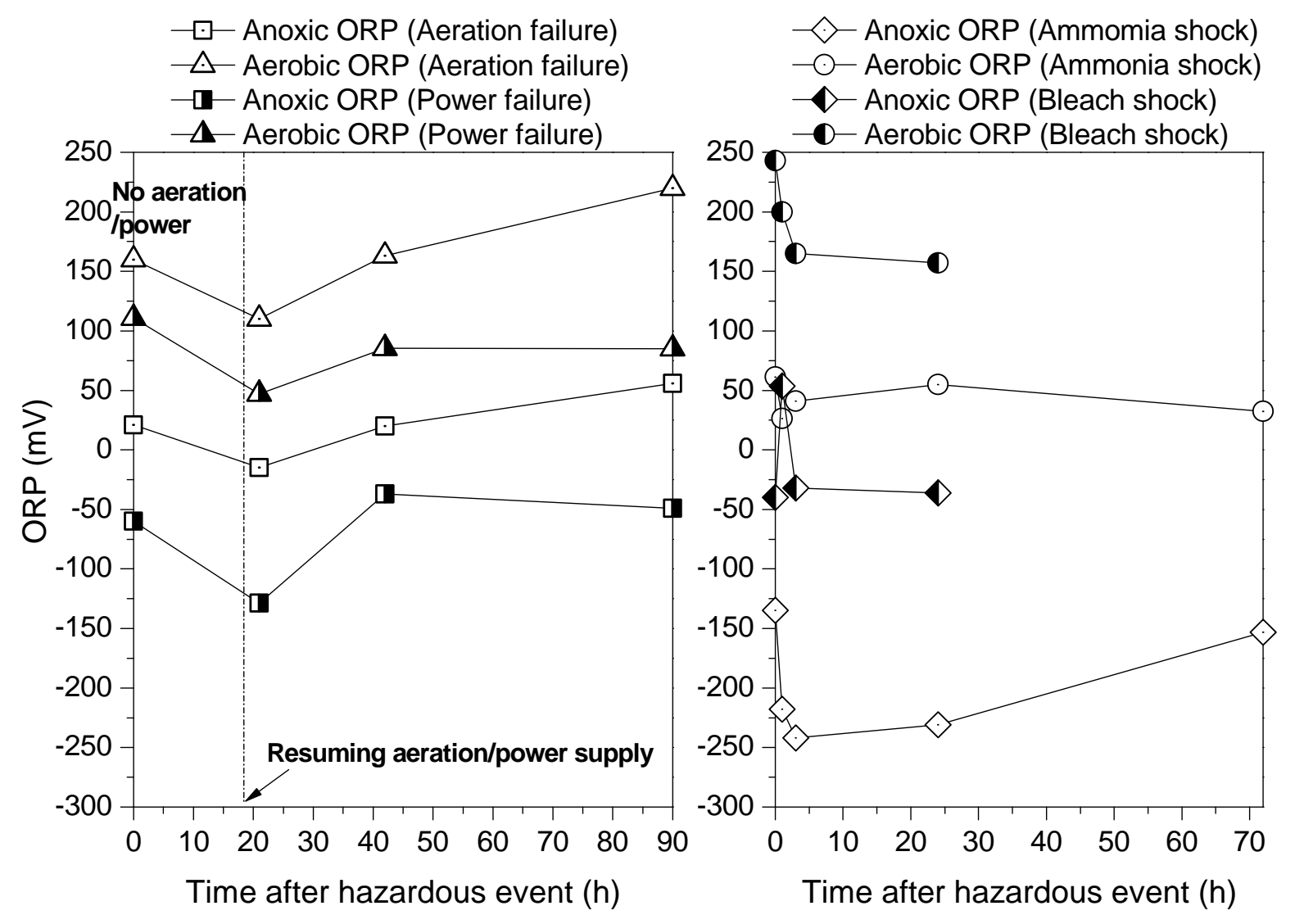

Figure S3: Impact of hazardous events on the oxidation-reduction potential (ORP) in anoxic and aerobic bioreactors of the MBR. 


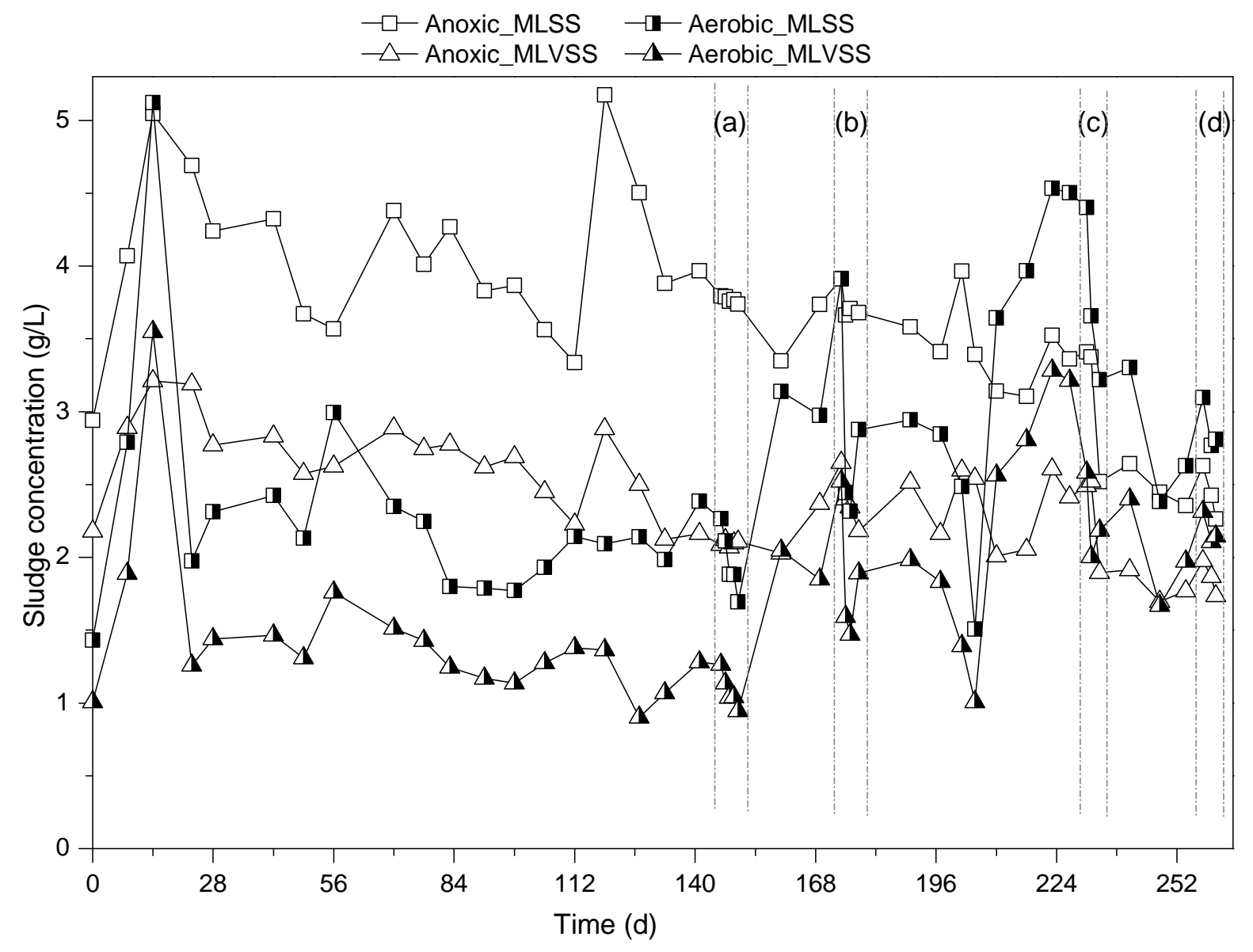

Figure S4: Sludge concentration profiles over the entire operation period of the MBR. The hazardous event tests were conducted in the following order: (a) aeration failure (Day 146 -150), (b) power failure (Day 174 - 178), (c) ammonia shock (Day 231 - 234) and (d) bleach shock (Day 258 - 261). The variations in MLSS and MLVSS profiles during normal operation period can be attributed to the variation in influent strength. 


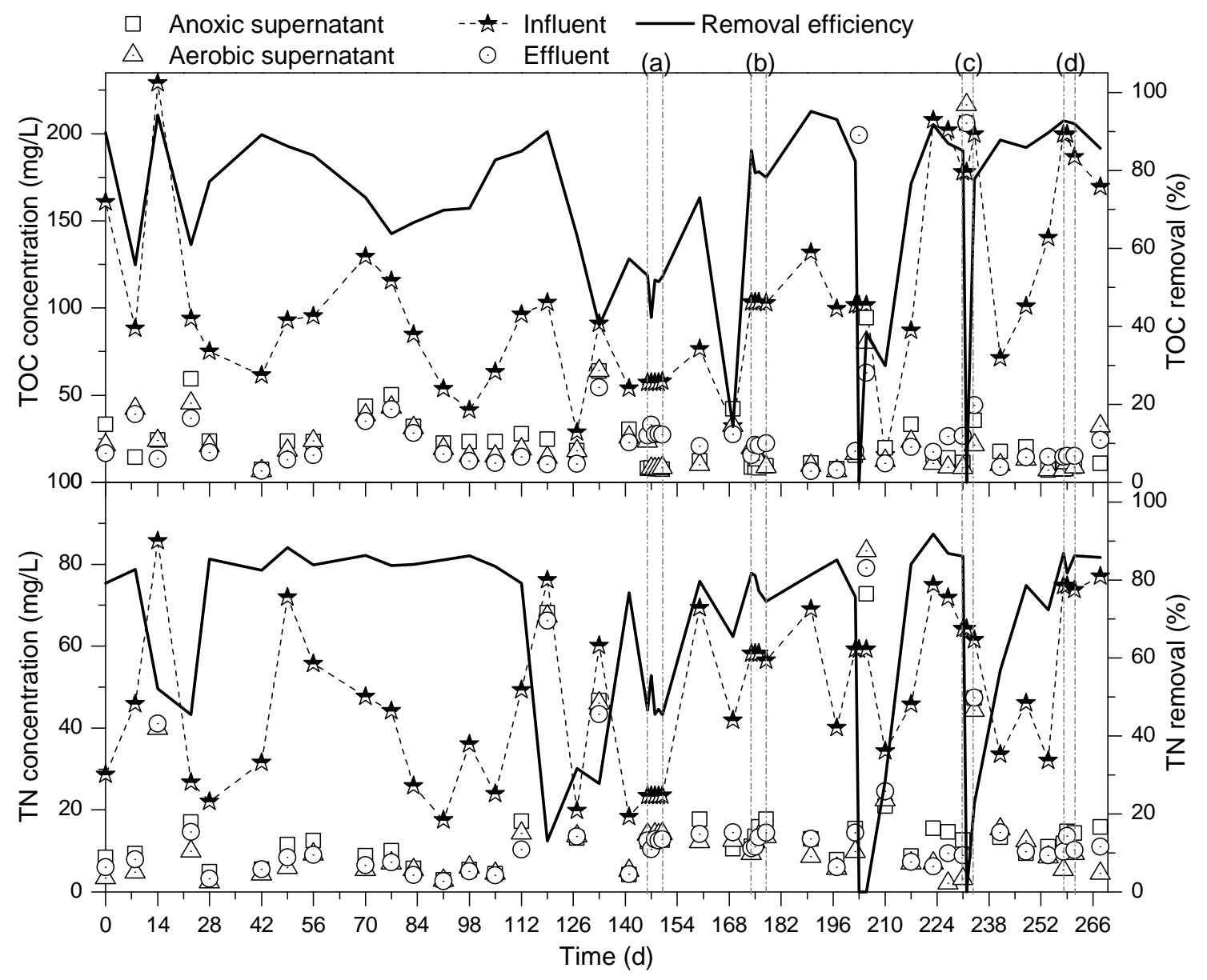

Figure S5: TOC and TN concentration and removal efficiency profiles over the entire operation period of the MBR. The hazardous events were conducted in the following order: (a) aeration failure (Day 146 -150); (b) power failure (Day 174 - 178); (c) ammonia shock (Day 231 - 234) and (d) bleach shock (Day 258 - 261). (Note: ammonia shock was initially attempted on Day 202, but later abandoned as it was found that prior to this attempt the mixing in anoxic reactor was operating inadequately for a day. The second attempt was made on Day 231 after stabilization of the reactor performance). 


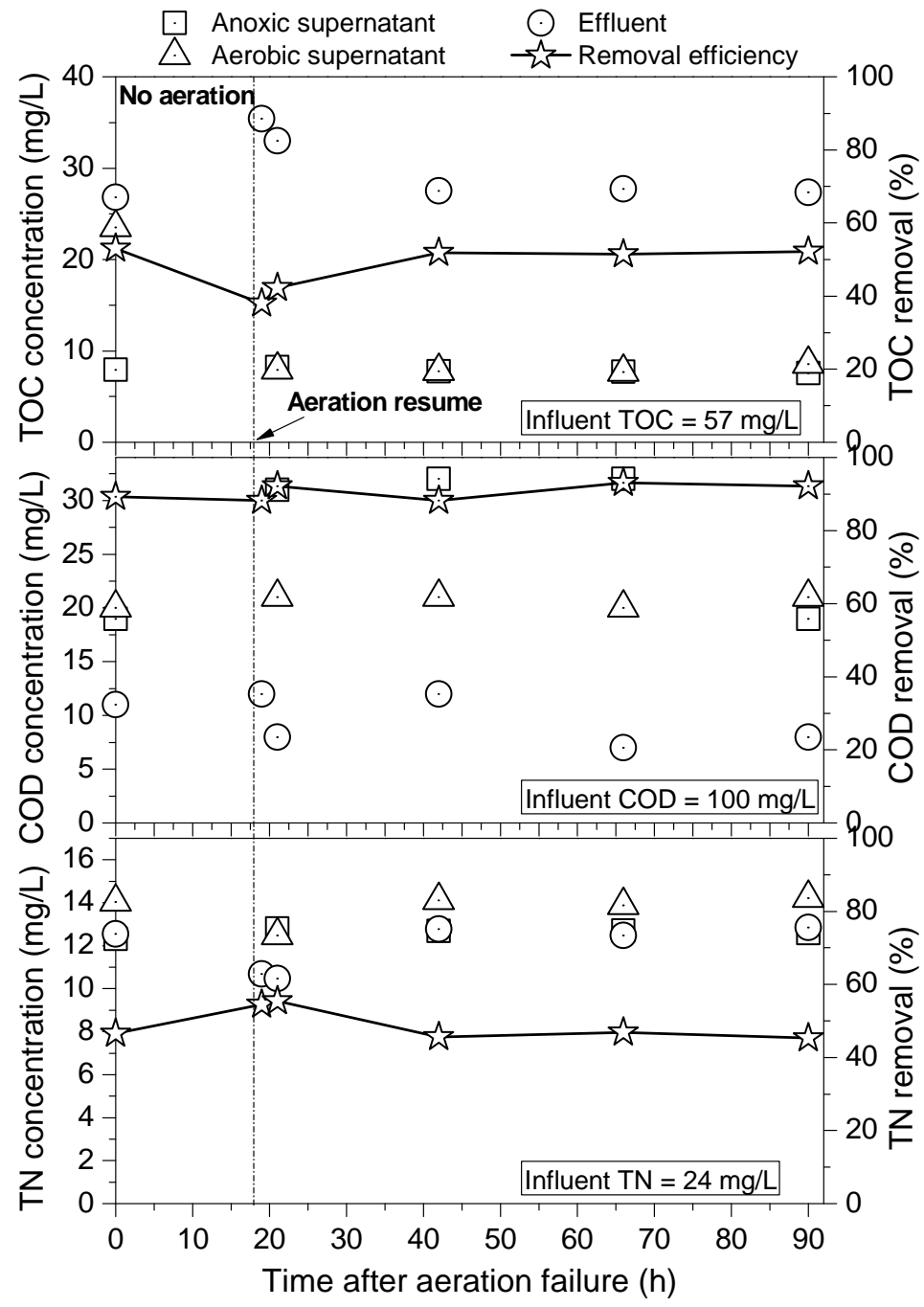

Figure S6: Impact of aeration failure on TOC/COD/TN removal performance by the MBR. Aeration was stopped for $18 \mathrm{~h}$, and removal performance was monitored in samples collected from the $19^{\text {th }}$ hour i.e., $1 \mathrm{~h}$ after resuming aeration. 


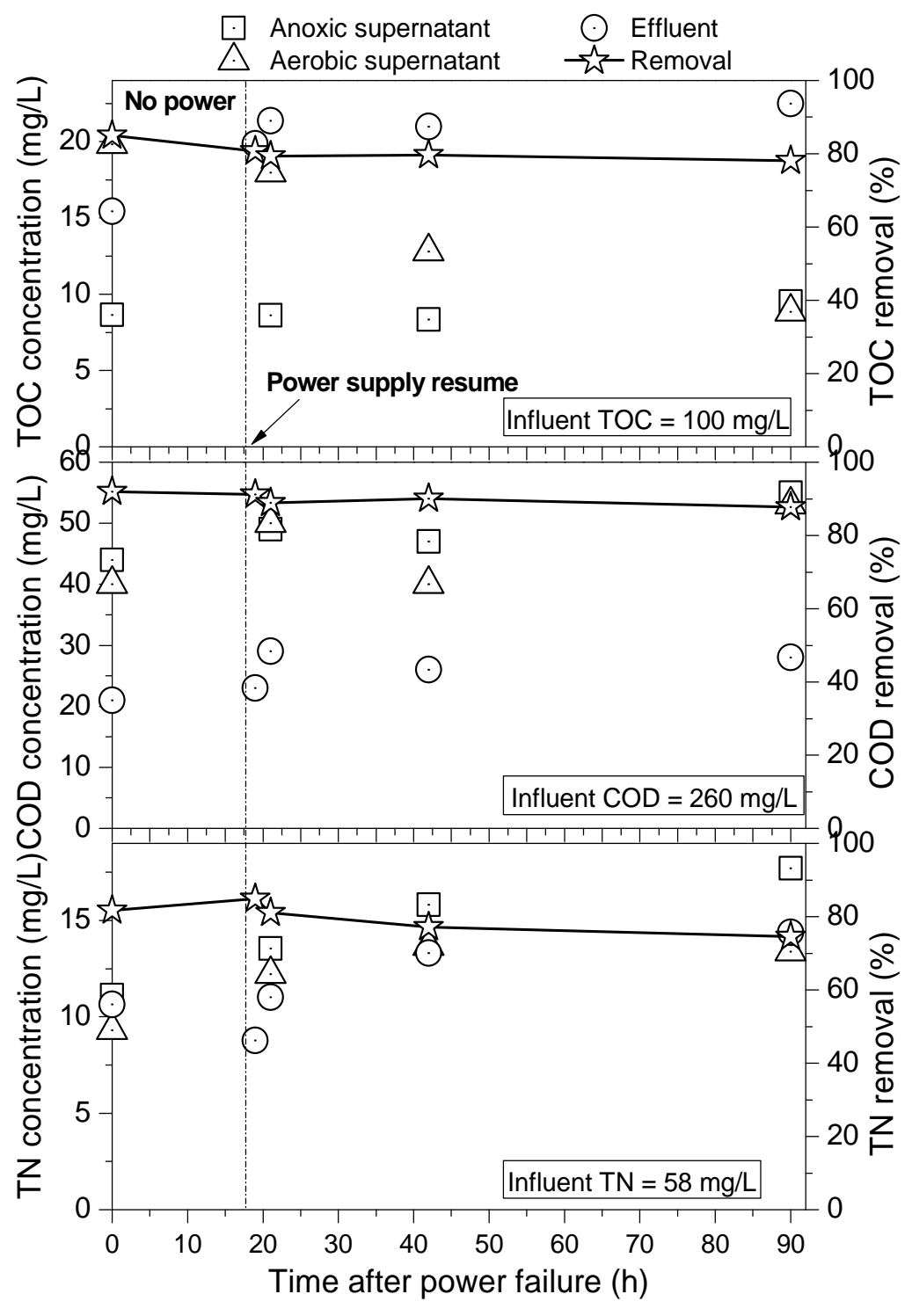

Figure S7: Impact of power failure on $\mathrm{TOC} / \mathrm{COD} / \mathrm{TN}$ removal performance by the MBR. Power supply was stopped for $18 \mathrm{~h}$, and removal performance was monitored in samples collected from the $19^{\text {th }}$ hour i.e., $1 \mathrm{~h}$ after resuming power supply. 


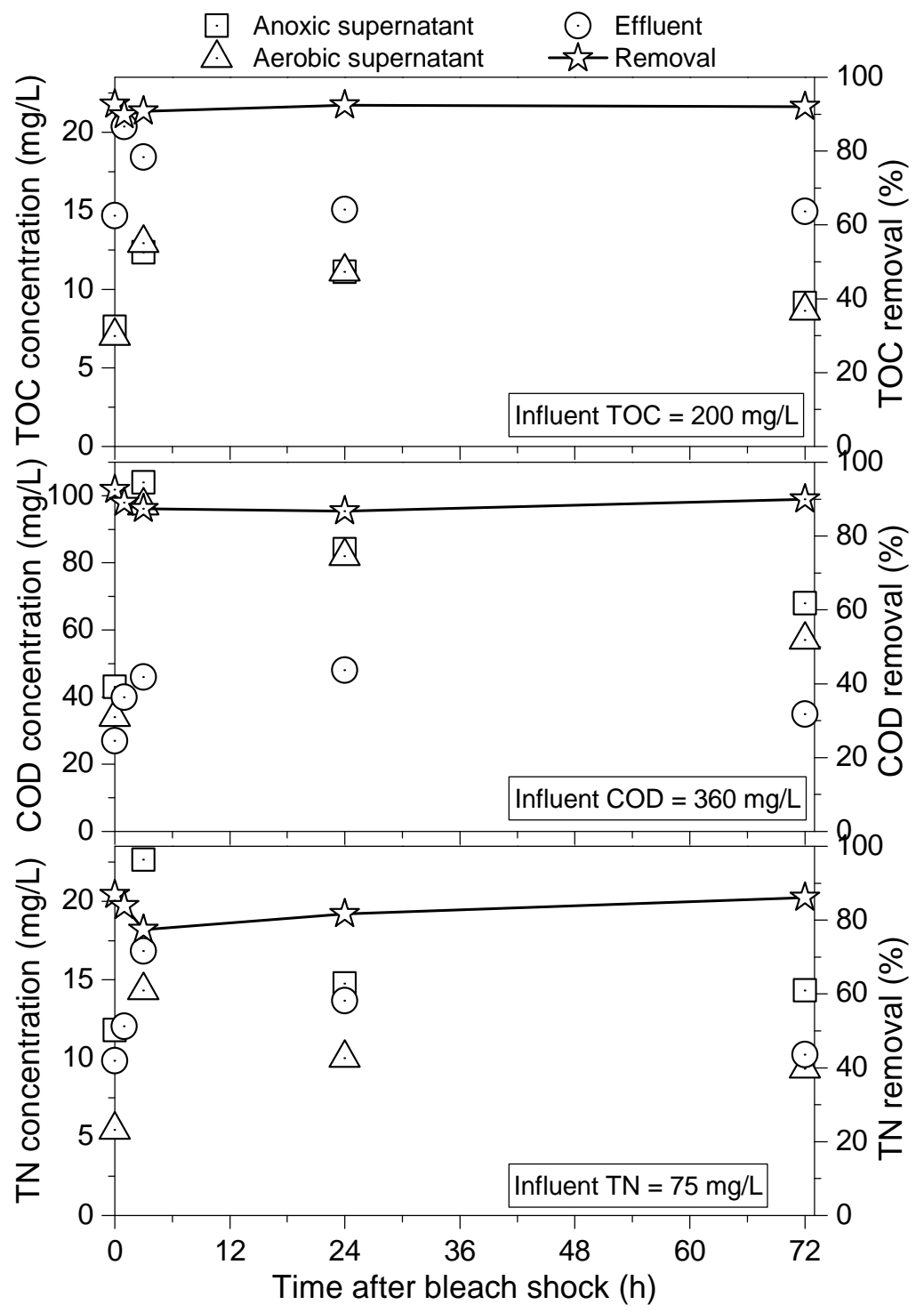

Figure S8: Impact of bleach shock on TOC/COD/TN removal performance by the MBR. 

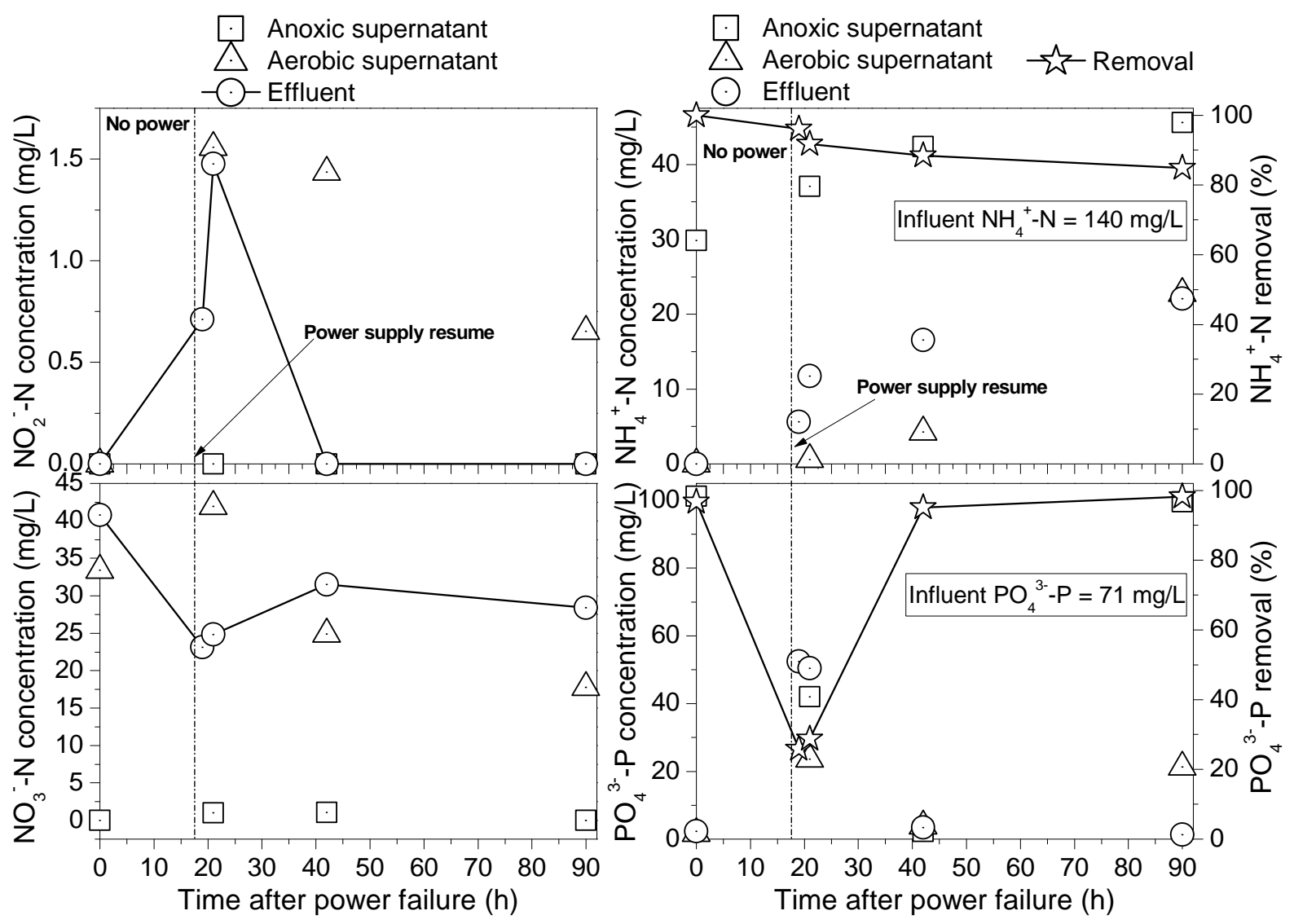

Figure S9: Impact of power failure on the formation of $\mathrm{NO}_{\mathrm{x}}{ }^{-} \mathrm{N}$ and the removal performance of $\mathrm{NH}_{4}{ }^{+}-\mathrm{N} / \mathrm{PO}_{4}{ }^{3-}-\mathrm{P}$ by the MBR. Power supply was stopped for $18 \mathrm{~h}$, and removal performance was monitored in samples collected from the $19^{\text {th }}$ hour i.e., $1 \mathrm{~h}$ after resuming power supply. 

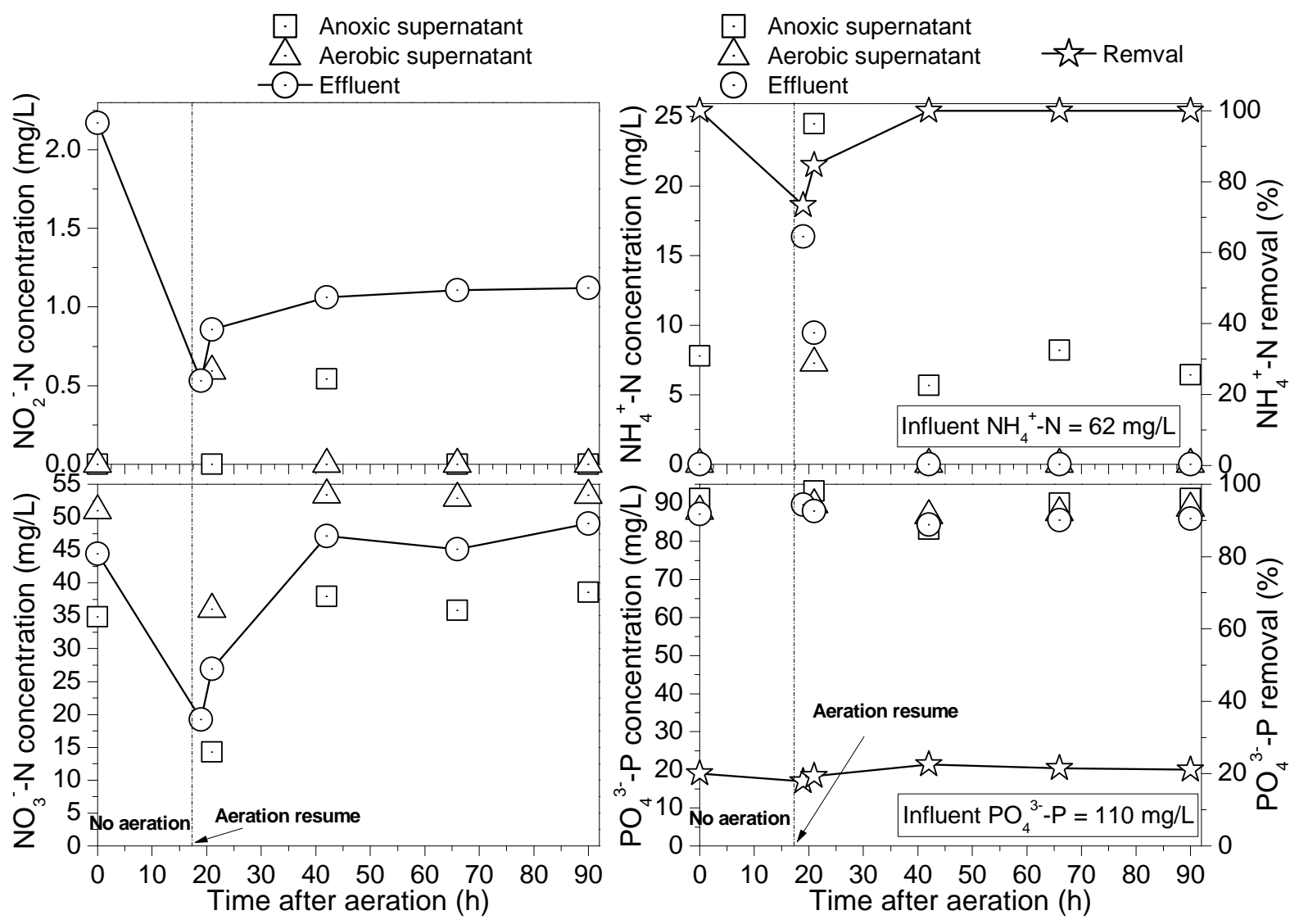

Figure S10: Impact of aeration failure on the formation of $\mathrm{NO}_{\mathrm{x}}{ }^{-}-\mathrm{N}$ and the removal performance of $\mathrm{NH}_{4}{ }^{+}-\mathrm{N} / \mathrm{PO}_{4}{ }^{3-}-\mathrm{P}$ by the MBR. Aeration was stopped for $18 \mathrm{~h}$, and removal performance was monitored in samples collected from the $19^{\text {th }}$ hour i.e., $1 \mathrm{~h}$ after resuming aeration. 


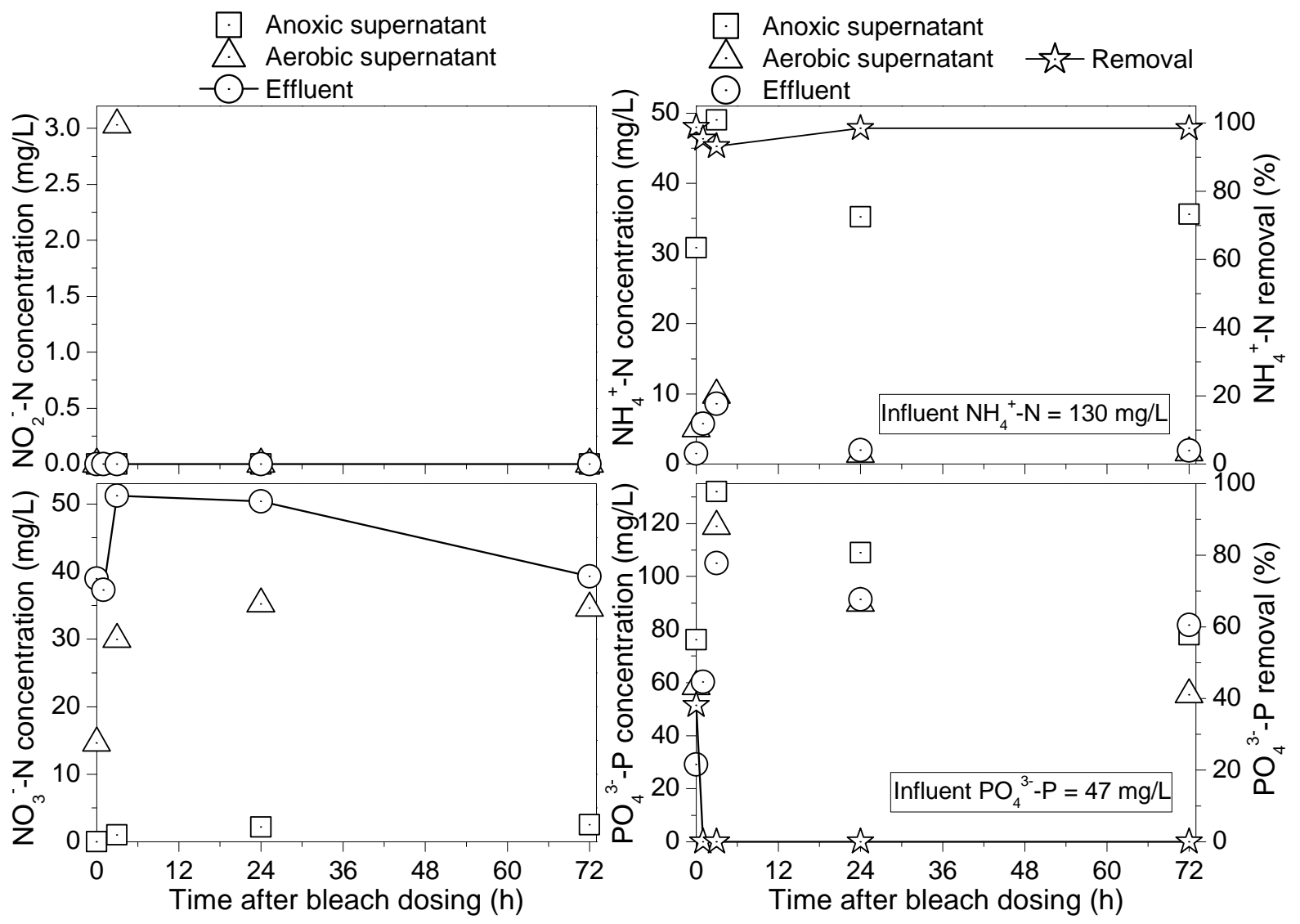

Figure S11: Impact of bleach shock on the formation of $\mathrm{NO}_{\mathrm{x}}{ }^{-} \mathrm{N}$ and the removal performance of $\mathrm{NH}_{4}{ }^{+}-\mathrm{N} / \mathrm{PO}_{3}{ }^{3-}-\mathrm{P}$ by the MBR. 


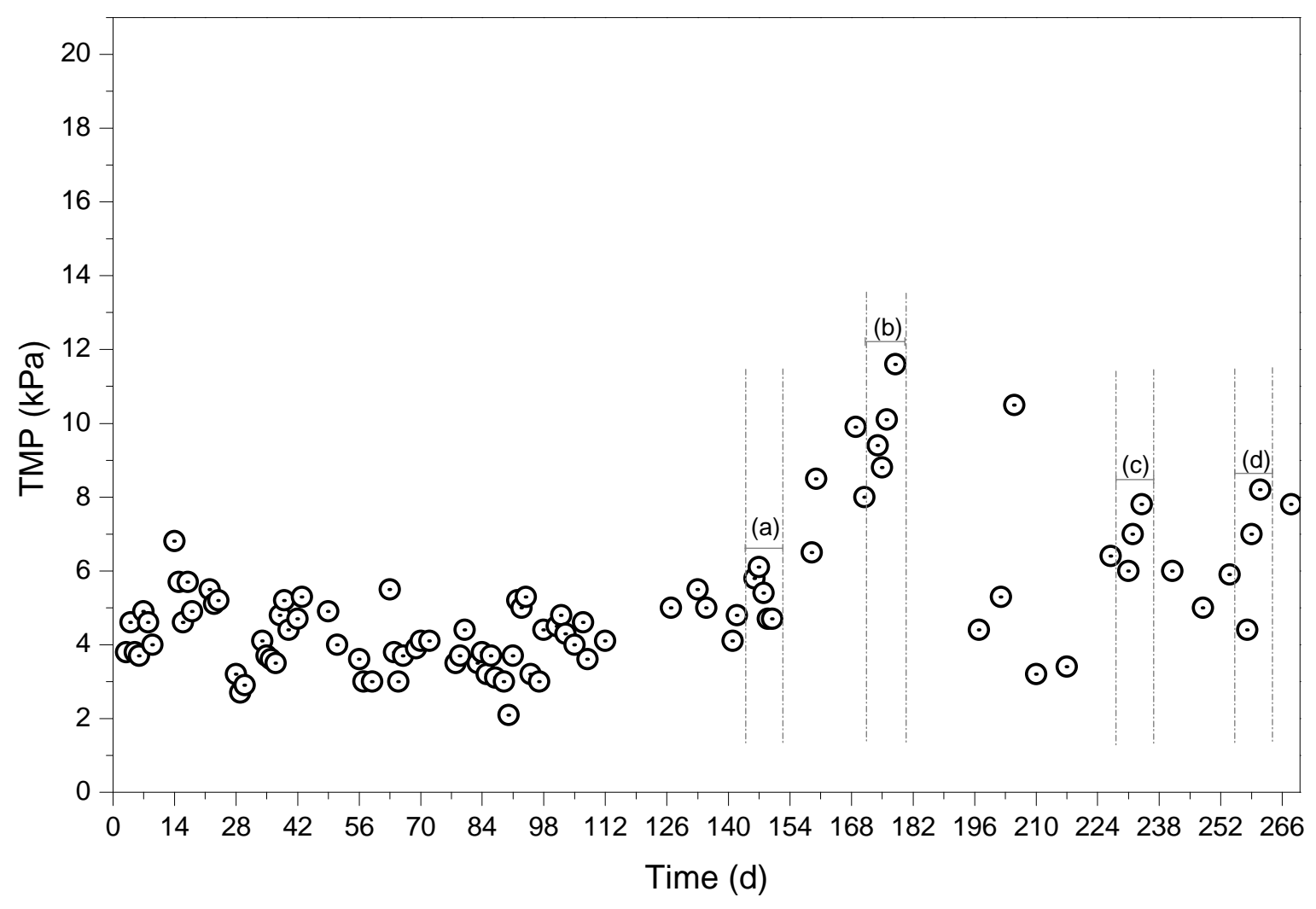

Figure S12: TMP profile over the whole operation period of the MBR. The periods of four hazardous events i.e., aeration failure, power failure, ammonia shock and bleach shock are indicated as (a), (b), (c) and (d), respectively. 